\title{
Research article \\ Optimization and green synthesis of zinc oxide nanoparticle using Garcinia cambogia leaf and evaluation of their antioxidant and anticancer property in kidney cancer (A498) cell lines
}

\author{
Varsha Jayakar ${ }^{1}$, Vinayak Lokapur ${ }^{1}$, Nityasree B. R. ${ }^{2}$, Raju Krishna Chalannavar ${ }^{2}$, Lyned D. Lasrado ${ }^{3}$, Manjula \\ Shantaram $^{4^{*}}$ \\ ${ }^{1}$ Research Scholar, ${ }^{4}$ Professor, Department of Studies and Research in Biochemistry, Mangalore University, Jnana Kaveri PG \\ Centre, Chikka Aluvara, Kodagu 571 232, Karnataka, India \\ ${ }^{2}$ Research scholar, ${ }^{2}$ Professor, Department of Applied Botany, Mangalore University, Mangalagangothri, 574199 Karnataka \\ India \\ ${ }^{3}$ Assistant Professor, Department of Post Graduate Studies and Research in Biochemistry, St. Aloysius College (Autonomous), \\ Mangalore, Karnataka, India
}

(Received: March 2021 Revised: May 2021 Accepted: June2021)

Corresponding author: Manjula Shantaram. Email: manjula59@gmail.com

\section{ABSTRACT}

Introduction and Aim: In $21^{\text {st }}$ century, nanomedicine has turned out to be an emergent modulus operation for the diagnosis and treatment of cancer. The current study includes the optimization and green synthesis of zinc oxide nanoparticles from the leaves of Garcinia cambogia and interpretation of its antioxidant and anticancer activity.

Materials and Methods: Synthesized ZnO NPs were investigated by UV-vis, FTIR, XRD, SEM, EDX, HR-TEM, SAED, particle size distribution and DLS analysis. Furthermore, different antioxidant assays were conducted for evaluating the antioxidant activity of (ZnO NPs) and its anticancer activity using (A498) cell lines along with noncancerous (HEK-293) cell line using MTT assay and XTT assay.

Results: The UV-visible spectrum showed an absorption peak at $277 \mathrm{~nm}$ that reflects surface plasmon resonance (SPR) ZnO NPs. The presence of various functional groups was confirmed by FTIR analysis. XRD patterns indicated that the ZnO NPs had a single-phase nature with the wurtzite structure. SEM, TEM pictures confirmed the size and shape of synthesized Nanoparticles ranges of 11-32 nm and mostly hexagonal forms. The Zeta potential value of $57.9 \mathrm{mV}$ revealed the surface charge of green synthesized $\mathrm{ZnO}$ NPs. The cytotoxicity of the ZnO NPs with various concentrations (6.25 to $200 \mu \mathrm{g} / \mathrm{mL}$ ) was measured in (A498) cell lines along with non-cancerous (HEK-293) cell line. After the exposure, to MTT and XTT assay, cellular morphology studies showed that the cancer cell viability decreased with increasing $\mathrm{ZnO}$ NP concentration.

Conclusion: The synthesized $\mathrm{ZnO}$ NPs via a green synthetic route could be developed as anti-cancer agent against cancer cells.

Keywords: Garcinia cambogia; green synthesis; zinc oxide nanoparticles; optimization; A498; HEK 293; renal cancer.

\section{INTRODUCTION}

$C$ ancer holds the top second cause when it comes to deadly disease of today's human population in entire Europe $(1,2)$. Among the 10 common death-causing cancers, kidney cancer is one of the debilitating health problems worldwide bannering renal cell carcinoma (RCC) as the most commonly known renal malignancy $(3,4)$. Couple of years ago, 1.8 crore (18 million) new cancer cases were diagnosed globally. RCC constituted around 2\% of them; although it is relatively rare compared to other cancers. Both incidence and mortality are raising in an alarming rate of $3 \%$ per decade. The diagnosing techniques for renal cancer have advanced in different methods over the past decades. Surgery is the best therapy for early-stage kidney cancer, but survival rate was hardly 1 year. Specific therapies prevailed for advanced kidney cancer in the clinic since the disease is unsusceptible to chemotherapy (5). Researchers all over the world are effectively working on exploring a cost-effective, eco-friendly anticancer drug with little or no side effects. In the last fifteen years, more than 1,100 anticancer drugs were developed. Out of which, most of them are in clinical trials whereas only few drugs are in favourable features to get the approval from Food and Drug Administration (1). In this regard, the development of nanoparticles (NP) based drugs have been effective in having minimal side effects and targeted action on cancer cells due to their large surface area. Especially inorganic NPs, including metal and metal oxides (gold, nickel, silver, iron oxide, zinc oxide, gadolinium, and titanium dioxide particles), are promising materials for their applications in medicines, such as cell imaging, biosensing, drug/gene delivery, and cancer therapy (6). Recent studies suggested that plants seem to be more advantageous and are proper for green production of nanoparticles in large scale where, the rate of synthesis is faster than that in the case of other 
organisms. In addition, the nanoparticles produced through plants varies in different shape and size in comparison with those produced by other organisms such as bacteria, fungi and algae; many bioactive constituents in plants such as alkaloids, terpenoids, flavonoids, amino acids, enzymes, vitamins, proteins, and glycosides could also be a participant in bioreduction, formation and stabilization of the metal nanoparticles (7).

Garcinia species are evergreen polygamous trees and shrubs covering a total of 400 species which can be seen in both the hemispheres of tropical forests. Seventeen out of thirty-five garcinia species are reported from Western ghats, India (8). Among which, GC are widely seen in the southern parts of Western Ghats, and are natively marketed as Kodampuli or Gummi Gutta. The presence of important bioactive compounds in GC leaves has been previously published (9). Based on the phytochemicals present, the current study was carried out in order to evaluate the cyto-toxicity using MTT and XTT assay. Literature reveals that anti-cancer activity of $G$. cambogia against various types of cancer like colon, adenocarcinoma (10), colorectal, cervical cancer (11) have been reported. Despite the claims and the use of GC for treating various cancers, little is known and documented. Garcinia species are also known to possess nutraceutical properties and proved to be rich sources of compounds with relevant therapeutical properties (12). Another possible application could be its utilization in the nanobiotechnology field.

Among the nanoparticles, zinc oxide ( $\mathrm{ZnO})$ NPs have received enormous interest for their implications for cancer therapy and has various advantages such as a high degree of cancer cell selectivity at physiological $\mathrm{pH}$ (6). ZnO NPs which can exhibit a wide variety of nanostructures are believed to be biosafe, nontoxic and biocompatible, been used in various technologies and industries such as optoelectronics, piezoelectric and magnetic sensors, bio-diagnosis, biological labelling, ceramic and rubber processing, environmental protection, biology and medicinal industry. Chemically, the surface of $\mathrm{ZnO}$ is rich in -OH groups, which permit $\mathrm{ZnO}$ to slowly dissolve in both acidic (e.g., the tumor cells and tumor microenvironment) and strong basic conditions. Based on this property, $\mathrm{ZnO}$ NPs have gained immense interest in biomedical (7). The extended application of $\mathrm{ZnO}$ NPs in medicine as anti-angiogenesis, antiplatelet agents, antiinflammatory, dental materials, cosmetics, drug and gene delivery, have made it a promising anticancer agent (13). This is the first report, as per our knowledge, in evaluating the possible beneficial interaction of aqueous extracts and zinc oxide nanoparticles on viability of the human renal cancer cell line (A498) and human embryonic renal cell line (HEK 293) by using MTT and XTT assay as an in- vitro technique as well as determining its selective cytotoxicity.

\section{MATERIALS AND METHODS}

\section{Collection and authentication of plants}

The plant leaves of G. cambogia was collected from the Central Horticultural Experiment Station, Chettalli, Kodagu district of Karnataka, India in the month of September 2020. The specimen was identified and authenticated by Principal Scientist at PND Herbarium, Mangalore, Karnataka, India vide letter no. SKPND: CR: 113: Herbarium Collection/1920. The herbarium is kept at PND Herbarium, Mangalore as G. cambogia (accession no. 9743) for further reference.

\section{Preparation of plant extracts}

Fresh plant leaves of G. cambogia (GC) was washed thoroughly in running tap water followed by deionised water, air dried under shade. The shade dried leaves were grinded into a fine powder using electric blender. The powder was stored in air tight brown bottle at $4^{\circ} \mathrm{C}$ for further use.

Aqueous leaf extract of Garcinia cambogia (GC): About 50 grams of dried leaves were grinded into a fine powder before mixing with $500 \mathrm{ml}$ of double distilled water and kept in a shaker incubator for 24 hrs. Temperature was adjusted at $37^{\circ} \mathrm{C}$ and the shaker incubator was set to $150 \mathrm{rpm}$. Muslin cloth was used to filter the extract followed by Whatman no. 1 filter paper. The filtrate was used for characterisation and synthesis of zinc oxide nanoparticles.

\section{Synthesis of zinc oxide nanoparticles (Gc-ZnO NPs)}

Zinc oxide nanoparticles were synthesized using zinc nitrate hexahydrate as described previously by Elham Zare et al., (2017) with slight modifications (14). Briefly, to $5 \mathrm{~mL}$ of GC extract and zinc nitrate was added in a glass beaker. The mixture was heated at $50^{\circ} \mathrm{C}$ till the volume reduces to half on a magnetic stirrer with 500rpm speed (REMI 2MLH). Transfer the solution into clean crucible and ignite at $400^{\circ} \mathrm{C}$ temperature in muffle furnace for 2 hours. White powder obtained confirms the formation of zinc oxide nanoparticles. After confirming the optimised shape and size from TEM analysis, bulk production was carried out to obtain large quantity of optimised $\mathrm{ZnO}$ NPs and stored at $4^{\circ} \mathrm{C}$ for further use.

\section{Optimization of zinc oxide nanoparticles}

Optimization of biomass concentration, metal ion concentration and temperature for green synthesis of zinc oxide nanoparticles was studied in order to maintain the shape, size, stability and enhance the product yield using following parameters (15).

Effect of plant extract concentration: Biomass concentration plays very important role in the 
synthesis of nanoparticle. The volume of GC $(2.5 \mathrm{~mL}$, $5 \mathrm{~mL}$ and $10 \mathrm{~mL}$ ) required to synthesize more yield is studied. Biosynthesis of Gc-ZnO NPs at different plant concentrations was characterized by UV-visible spectrophotometer.

Effect of temperature: Temperature plays very crucial role in all reactions. Optimization studies with respect to temperature were carried out with temperature ranging from $400^{\circ} \mathrm{C}$ to $600^{\circ} \mathrm{C}$ with difference of $100^{\circ} \mathrm{C}$ on GC extract for Gc-ZnO NPs production. The sample was analysed with UV-visible spectrophotometer and further impact of temperature on nanoparticles was studied.

Effect of $\mathrm{ZnNo}_{3}$ concentration: The synthesis of nanoparticles is greatly dependent on substrate concentration. The quantity of Gc-ZnO NPs from $50 \mathrm{mM}$ to $100 \mathrm{mM}$ was studied with a difference of $25 \mathrm{mM}$. The optimum concentration for the production of Gc-ZnO NPs is confirmed by UV-vis spectrophotometer.

\section{Biosynthesized ZnO NPs characterization}

The synthesized Gc-ZnO NPs were characterized using various spectroscopic and microscopic techniques.

\section{Optical property of ZnO NPs by UV-vis spectroscopy}

To determine the optical property of the synthesized Gc-ZnO NPs, small amount of the nano powder was re-suspended in about $5 \mathrm{~mL}$ of de-ionized water and scanned between 190 to $800 \mathrm{~nm}$ in UV-vis spectrophotometer (Shimadzu UV-1800) and measured the maximum absorbance. Sharp peak given by UV-visible spectrum confirms the zinc oxide nanoparticle at the absorption range between 260 and $280 \mathrm{~nm}$.

\section{FT-IR spectral analysis}

Phytochemical constituents of dried leaf powder and functional groups of synthesized Gc-ZnO NPs were subjected to FTIR analysis (SHIMADZU). The samples were grinded with $\mathrm{KBr}$ pellets and measured in FTIR spectrum in the range of $4000-400 \mathrm{~cm}^{-1}$. The probable biomolecules responsible for reduction, capping, and effective stabilization of the Gc-ZnO NPs were recorded using FTIR spectrophotometer at diffuse reflectance mode.

\section{$\mathrm{X}$-ray diffraction analysis}

X-ray diffraction (XRD) of Gc-ZnO NPs were analysed using (Xpert MPD, Make: Philips, Holland) with operating current at $30 \mathrm{~mA}$ and the voltage at 40 $\mathrm{kV}$. The scanning was done from $5-100^{\circ}$

Scanning electron microscope (SEM) and Energy Dispersive Analysis X-Ray (EDAX)

Morphological characters of green synthesized $\mathrm{ZnO}$ nanoparticles were analysed by SEM (ZEISS). For this electron microscopic study, the sample was made into thin films by placed on a carbon coated copper grids and the images were recorded. In addition, Energy Dispersive Spectroscopy (EDS) or Energy Dispersive Analysis X-Ray (EDAX) characterized the presence of elemental zinc in the sample.

\section{High Resolution Transmission electron microscope (HR-TEM) and SAED pattern}

The size, shape and dispersal were analysed using the high-resolution images obtained with a transmission electron microscope (Jeol/JEM 2100). It is operated at the voltage of $200 \mathrm{kV}$. The sample was sonicated for $5 \mathrm{~min}$ and the diluted sample was placed onto copper grid and allowed to dry and images recorded at different magnification power. Selected area diffractogram was used to analyse the crystalline structure of synthesized Zinc Nanoparticles.

\section{Particle size distribution and Dynamic Light Scattering (DLS)}

The average particle size was measured by Zeta sizer (SZ-100, Horiba scientific). For the determination of particle size, sterile de-ionized water was used to disperse the nano powder and sonicated for $10 \mathrm{~min}$ for the uniform dispersion in the de-ionized water. DLS of this nanopowder suspension was carried out using Zeta sizer. Based on the function of time, average particle size as hydrodynamic diameter and polydispersity index were measured.

\section{In vitro methods to determine antioxidant activity}

Ferric ion reducing antioxidant power (FRAP) assay

FRAP assay was used to measure the total antioxidant power of the extracts. The FRAP assay was performed according to Lokapur et al., (2020) with slight modifications (16). Aqueous plant extract of GC extracts and $\mathrm{ZnO}$ NPs in different concentrations, ranging from $12.5 \mu \mathrm{g}$ to $200 \mu \mathrm{g} / \mathrm{ml}$ were mixed with $2.5 \mathrm{~mL}$ of $0.2 \mathrm{mM}$ phosphate buffer ( $\mathrm{pH} 7.4)$ and 2.5 $\mathrm{mL}$ of potassium ferricyanide $[1 \%$ weight/volume $(\mathrm{W} / \mathrm{V})]$. Temperature was set to $50^{\circ} \mathrm{C}$ and the resulting mixture is incubated for 20 minutes. $2.5 \mathrm{~mL}$ of trichloroacetic acid $(10 \% \mathrm{~W} / \mathrm{V})$ was added and centrifuged for 10 minutes (3000 rpm). Then, $2.5 \mathrm{~mL}$ of deionised water was added followed by $0.5 \mathrm{~mL}$ of ferrous chloride $(0.1 \% \mathrm{~W} / \mathrm{V})$. Finally, the absorbance was measured at $700 \mathrm{~nm}$. Ascorbic acid was used as positive reference standard.

\section{Phosphomolybdenum (PM) assay}

The total antioxidant activity was estimated by phosphomolybdenum (PM) assay using the standard procedure (16). Aqueous plant extract of $\mathrm{GC}$ and $\mathrm{ZnO}$ NPs in different concentration ranging from 12.5, 25, $50,100,200 \mu \mathrm{g} / \mathrm{ml}$ were added to each test tube individually containing $3 \mathrm{~mL}$ of deionised water and 1 $\mathrm{mL}$ of molybdate reagent solution. These tubes were 
kept incubated at $95^{\circ} \mathrm{C}$ for 90 minutes. After incubation, they were kept at room temperature for 2030 minutes and the optical density was measured at $695 \mathrm{~nm}$. Ascorbic acid was used as the reference standard.

\section{2, 2-Diphenyl-1-picrylhydrazyl radical scavenging ability (DPPH) assay}

Free radical scavenging effect of aqueous plant extract was determined using the 2-diphenyl- 1 picrylhydrazyl (DPPH) method described by Lokapur et al., (2020) with slight medications (16). Briefly, the concentrations $(12.5,25,50,100,200 \mu \mathrm{g} / \mathrm{ml})$ of GC extracts and $\mathrm{ZnO}$ NPs were prepared. DPPH solution $(0.004 \%)$ was prepared in ethanol and $1 \mathrm{ml}$ of this solution was mixed with the same volume of aqueous leaf extracts and standard ascorbic acid solution separately. The mixture was kept for incubation in the dark under room temperature for 30 minutes and the absorbance was measured at $517 \mathrm{~nm}$. The degree of DPPH-purple decolourization to DPPH yellow confirmed the scavenging efficiency of the extract. Higher free radical-scavenging activity was observed as the absorbance of the reaction mixture was decreased. To calculate the scavenging activity, the following formula was used:

DPPH scavenging activity $(\%)=\mathrm{A}_{\mathbf{C}}-\mathrm{A}_{\mathbf{T}} / \mathrm{A}_{\mathbf{C}} \times 100$

Where $A_{C}$ is the absorbance of the control reaction (1 $\mathrm{ml}$ of ethanol with $1 \mathrm{ml}$ of DPPH solution), $\mathrm{A}_{T}$ is the absorbance of the test sample. The results were analysed in triplicates. The $\mathrm{IC}_{50}$ value represents the concentration of sample required to inhibit $50 \%$ of the DPPH free radical.

\section{In vitro cytotoxicity assay}

\section{Culturing of cell lines}

The human renal carcinoma cells (A498) and Human embryonic kidney cells (HEK 293) were procured from the National Centre for Cell Sciences (NCCS), Pune, India. Dulbecco's Modified Eagle Media (DMEM) with low glucose (Gibco, Invitrogen, USA) was used for maintaining the cell line, which was supplemented with 10\% Fetal Bovine Serum (FBS, Gibco, Invitrogen, USA). Antimycotic 100X solution (Thermofisher Scientific) were added to the medium to prevent bacterial contamination. The medium with cell lines was maintained in a humidified environment with $5 \% \mathrm{CO}_{2}$ at $37{ }^{\circ} \mathrm{C}$. On reaching $80 \%$ confluency, cells were detached by treatment with trypsin-EDTA and reseeded in fresh media.

\section{Treatment groups}

The cytotoxic activity of the aqueous extracts of GC and $\mathrm{ZnO}$ NPs was evaluated using MTT (3- $(4,5-$ dimethylthiazol -2- yl)- 2,5 diphenyl tetrazolium bromide) assay and XTT assay by following Sudha et al., 2020 with slight modifications (17). Briefly, A498 human kidney cancer cells and HEK293 human embryonic kidney cells were seeded at a density of 1 $\times 10^{4}$ cells per well in 96-well flat-bottom micro plate and maintained at $37^{\circ} \mathrm{C}$ in $95 \%$ humidity and $5 \% \mathrm{CO}_{2}$ humidified atmosphere for overnight before the treatment. These cells were treated with a different concentration range of GC and Gc-ZnO NP extracts $(6.25-200 \mu \mathrm{g} / \mathrm{mL})$ followed by incubation for 48 hours respectively. Cisplatin was used as standard drug to compare the effects induced for HEK293 human embryonic kidney cell and A498 human kidney cancer cell lines.

The current study carried out the treatment groups as follows:

Negative control: cells alone.

Positive control: cells + cisplatin.

Test groups: cells+ aqueous G. cambogia extract and Cells $+\mathrm{ZnO}$ NPs

Same treatment group was followed for human embryonic kidney cell (HEK-293) normal cell lines.

\section{MTT Cell viability assay}

After $48 \mathrm{~h}$ incubation, the images were captured using phase contrast microscopy. During successive follow up, cells attached to the well were washed twice with Phosphate buffer saline (PBS). Then, $20 \mu \mathrm{L}$ of MTT staining solution was added to each well and further incubated at $37^{\circ} \mathrm{C}$ for next $4 \mathrm{hrs} .100 \mu \mathrm{L}$ of DMSO was added to each well to dissolve the formazan crystals, and absorbance was read spectrophotometrically at $570 \mathrm{~nm}$ against the control using micro plate reader (Bio-Rad, California, USA). Procedure was repeated for three times and the percentage of the average was considered for the conclusion. The survival percentage was plotted against control (untreated) group using the following equation:

Surviving cells $(\%)=($ Mean OD of test compound $/$ Mean OD of Negative control $) \times 100$

\section{XTT Cell Viability assay}

After $48 \mathrm{~h}$ incubation, removed the plates from incubator and added 50 $\mu 1$ activated XTT reagent. Plates were incubated for 2 to 4 hours once again in incubator. After completion of incubation, absorbance was recorded using microplate reader (Bio-Rad, California, USA) at an absorption wavelength of $450 \mathrm{~nm}$.

Surviving cells $(\%)=($ Mean OD of test compound / Mean OD of Negative control) $\times 100$

\section{Selectivity index (SI)}

The A498 and HEK293 cells were used to measure the SI. The SI, which represents the cytotoxic selectivity (i.e., drug safety), for both GC extract and Gc-ZnO NPs was calculated using the following formula (18).

SI $=\mathrm{IC}_{50}$ calculated for normal cell line/ $\mathrm{IC}_{50}$ calculated for cancer cell line 
The SI value $>2$ is considered as high selectivity.

\section{Statistical analysis}

The study was carried out in triplicates and results were expressed as mean $\pm \mathrm{SD}$. Statistical significance between groups was analysed using two-way ANOVA $(* * * p<0.001)$ in GraphPad Prism 5 Software.

\section{RESULTS}

\section{Optimization of Gc-ZnO NPs}

Optimization of reaction conditions like the quantity of GC extract, precursor metal ion concentration and temperature were carried out using UV- visible spectrophotometer.

\section{Effect of plant extract concentration}

The UV- visible spectra depicted in Fig. 1, describes the impact of varying volumes of GC at 400, 500 and $600^{\circ} \mathrm{C}$ respectively, on the biosynthesis of $\mathrm{Gc}-\mathrm{ZnO}$ NPs. A steady improvement in the absorption and peak prominence was observed when increasing the extract volume from $2.5 \mathrm{~mL}$ to $10 \mathrm{~mL}$. Maximum absorption was observed with $5 \mathrm{~mL}$ of G. cambogia extract in 50 $\mathrm{mM}$ of zinc nitrate. Any increase or decrease in this volume led to decrease in the absorption values leading to broad SPR bands due to agglomeration of the nanoparticles. Thus, the volume of GC extract played a crucial part in deciding the size distribution of Gc-ZnO NPs and $5 \mathrm{~mL}$ was found to be the optimum quantity of extract required for the biosynthesis.

\section{Effect of temperature}

Temperature is one of the crucial factors affecting the Gc-ZnO NPs production. The effect of varying temperatures on Gc-ZnO NPs production using GC extract is carried out at different temperatures from

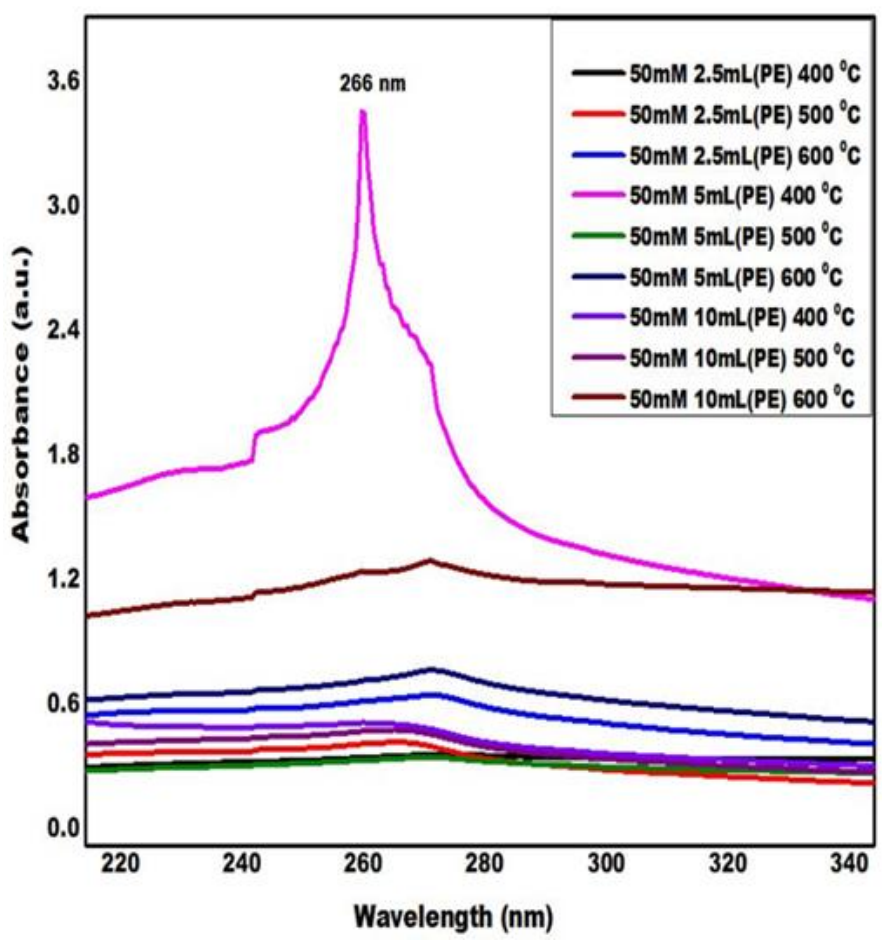

400 to $600^{\circ} \mathrm{C}$ and the maximum production of $\mathrm{Gc}-\mathrm{ZnO}$ NPs was obtained at $400^{\circ} \mathrm{C}$ in $50 \mathrm{mM}$ concentration compared to other temperatures and also sharp peak was detected by UV-vis spectrophotometer at $266 \mathrm{~nm}$. On the other side, it is clear that with rise in temperature from $400^{\circ} \mathrm{C}$, the absorption bands of Gc$\mathrm{ZnO}$ NPs showed similar patterns with low and extremely broad peaks. This phenomenon is due to an increase in the particle size at high temperature owing to the agglomeration of particles. Thus, effect of temperature plays a significant role in determining the morphological characteristics of the nanoparticles and $400^{\circ} \mathrm{C}$ was considered as optimum temperature.

\section{Effect of Gc-ZnO NPs concentration}

Another important parameter in obtaining the optimum biosynthesis is the concentration of zinc nitrate on the production of Gc-ZnO NPs. From the spectra, it is clear that, the optimum substrate concentration required was $50 \mathrm{mM}$ by UV-vis spectrophotometer at the maximum wavelength of $266 \mathrm{~nm}$. Further increase in the concentration to $75 \mathrm{mM}$ and $100 \mathrm{mM}$ resulted in a shift towards broader wavelength due to the increase in particle size. Hence, it was concluded that increasing the concentration of metal ions beyond a threshold value led to decrease in the synthesis of nanoparticles using GC extract and $50 \mathrm{mM}$ is considered as optimum.

After determining the optimal conditions in each of the effective parameters, $(50 \mathrm{mM}$ of zinc nitrate, $5 \mathrm{~mL}$ of GC extract and calcination at $400{ }^{\circ} \mathrm{C}$ temperature), the Gc-ZnO NPs were synthesized and was characterized using various physico-chemical parameters to ascertain their size, shape and functionalization.

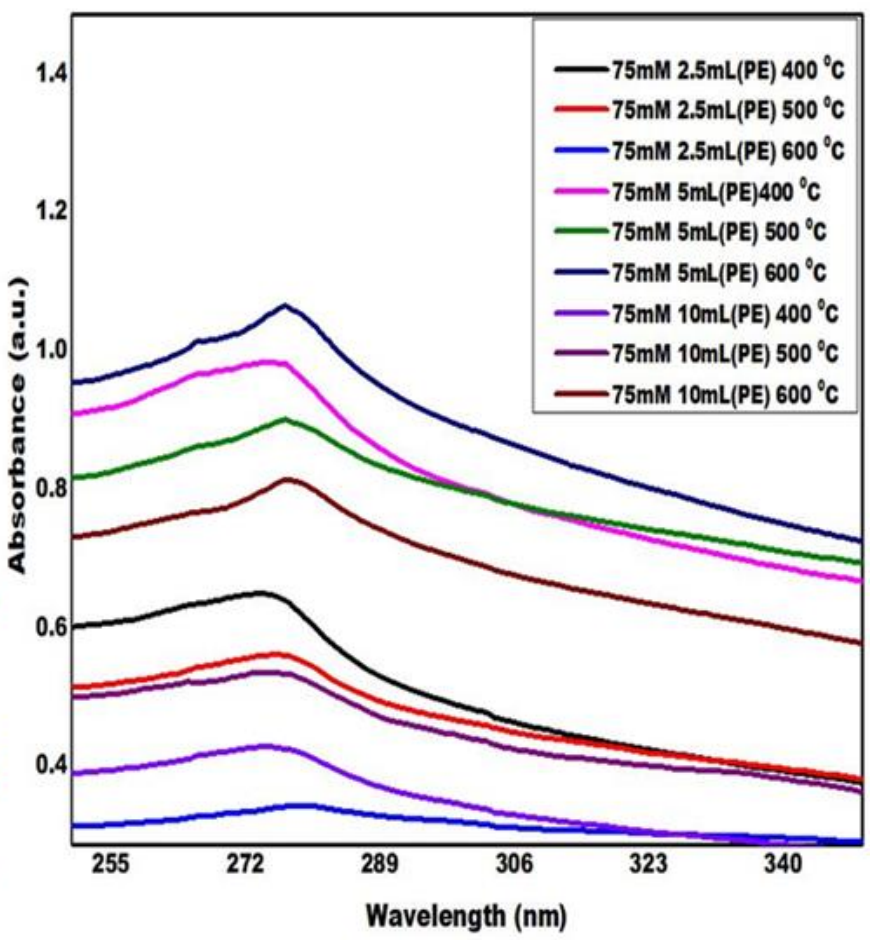




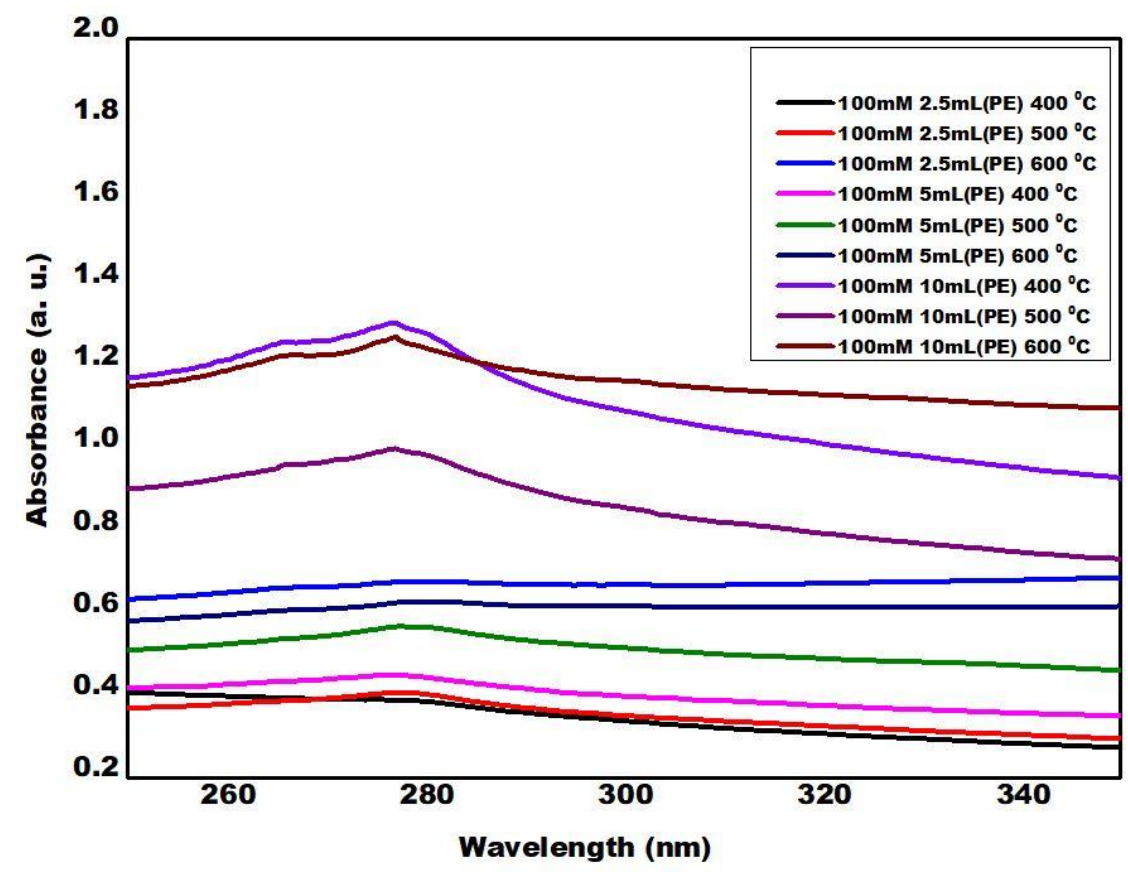

Fig. 1: Effect of extract concentration, metal concentration and temperature

\section{Characterization studies of Gc-ZnO NPs at optimum conditions}

\section{UV-vis spectrophotometer}

In the present research, Gc-ZnO NPs were synthesized using leaf extract of Garcinia camobogia at optimum conditions. The nano powder was redispersed in the double distilled water to examine UV-VIS spectra, which exhibited the sharp absorption with all variables at their optimum values $(266 \mathrm{~nm})$, which was assigned to the intrinsic band gap of $\mathrm{Zn}-\mathrm{O}$ absorption (Fig. 2). An intense peak in the spectra shows that the particles are nano sized.

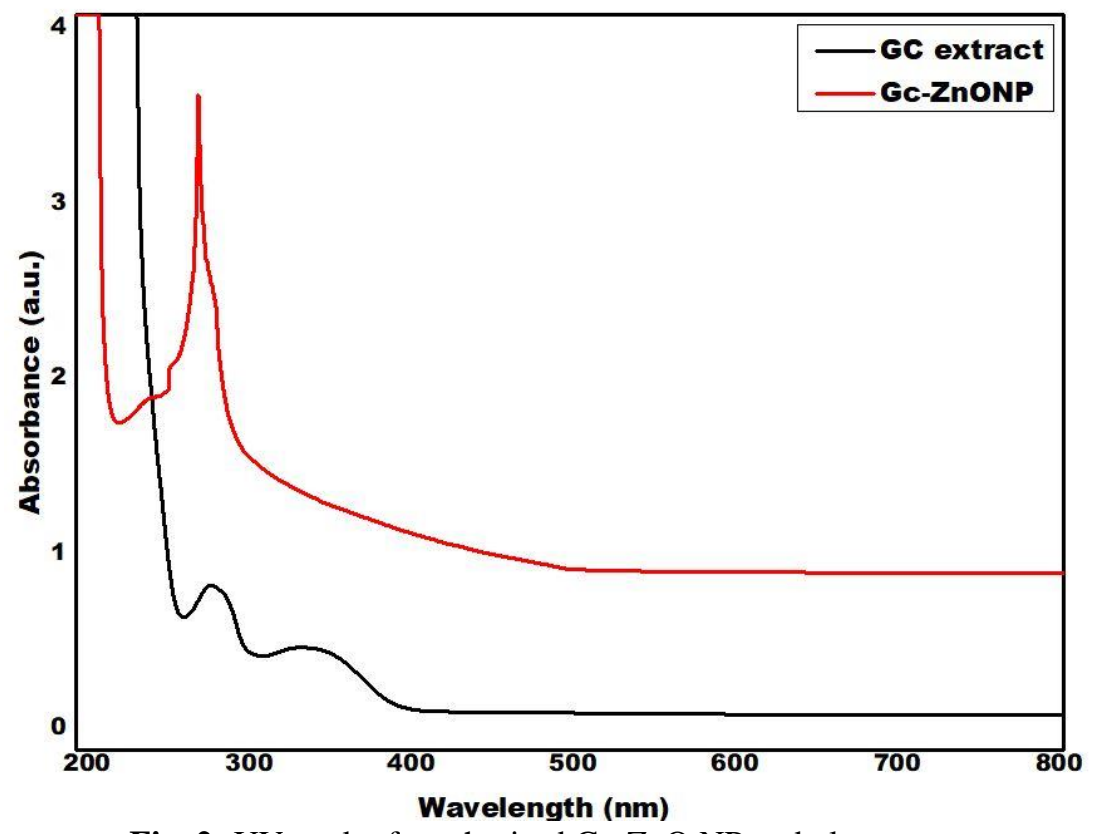

Fig. 2: UV-peak of synthesised Gc-ZnO NP and plant extract

\section{FTIR}

FTIR spectrum of GC leaf extract has shown strong absorption bands at $3294.42 \mathrm{~cm}^{-1}$ and $2931.80 \mathrm{~cm}^{-1}$ representing $\mathrm{O}-\mathrm{H}$ and $\mathrm{C}-\mathrm{H}$ stretching of alcohols, polyphenols and alkenes respectively. The sharp peaks observed at $1728.22 \mathrm{~cm}^{-1}$ corresponds to $\mathrm{C}=\mathrm{O}$ stretching vibrations due to acid of anhydrides. The peak at $1602.85 \mathrm{~cm}^{-1}$ and $1406.11 \mathrm{~cm}^{-1}$ were attributed to $\mathrm{C}=\mathrm{C}$ stretching of alkenes and $\mathrm{C}-\mathrm{H}$ stretching vibrations due to Alkanes respectively. Alkyl halides were represented by $-\mathrm{C}-\mathrm{H}$ wag- weak stretching at $1207.44 \mathrm{~cm}^{-1}$. The aromatic C-H functional group at the wave number of $765.74 \mathrm{~cm}^{-1}$ and $607.58 \mathrm{~cm}^{-1}$ are related to the symmetrical stretching mode and bending mode of $\mathrm{C}-\mathrm{H}-\mathrm{H}$ bands respectively.

The FT-IR spectra of ZnO NPs were shown in the figure 3 in which the metal oxide $(\mathrm{ZnO})$ stretching 
vibration peaks were observed at $428.20 \mathrm{~cm}^{-1}$ and $486.06 \mathrm{~cm}^{-1}$. The intense band at $1411.89 \mathrm{~cm}^{-1}$ is due to the presence of tertiary alcohol $(\mathrm{CAOH})$ group. O-

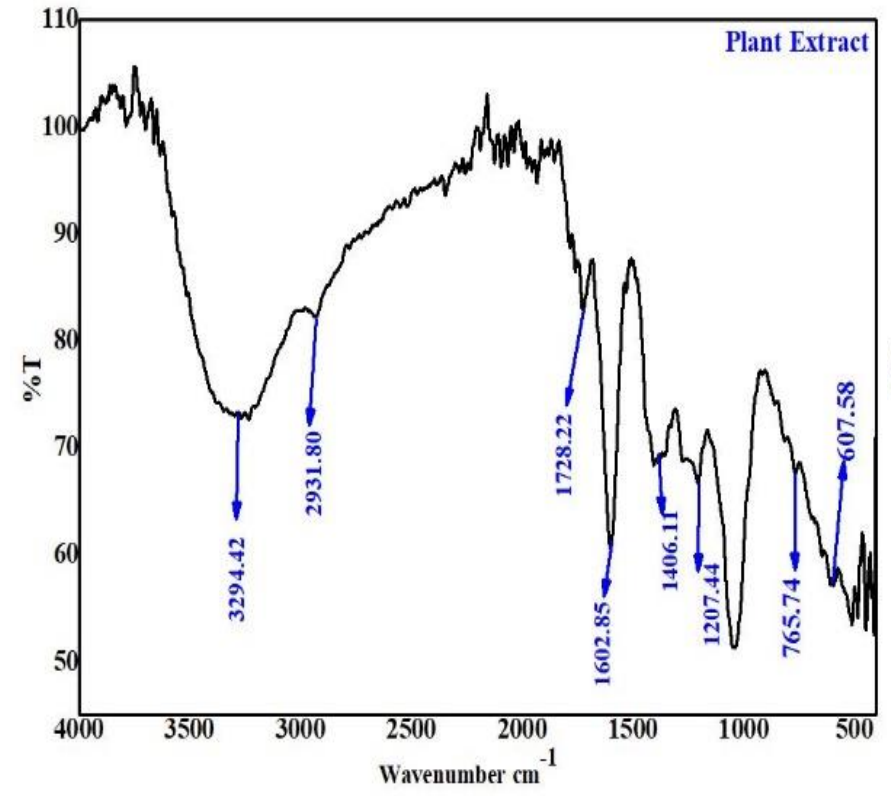

stretch while $877.61 \mathrm{~cm}^{-1}$ is corresponded to $\mathrm{CH}$ stretch and thus FT-IR spectra confirms the synthesis of $\mathrm{ZnO}$ nanoparticles.

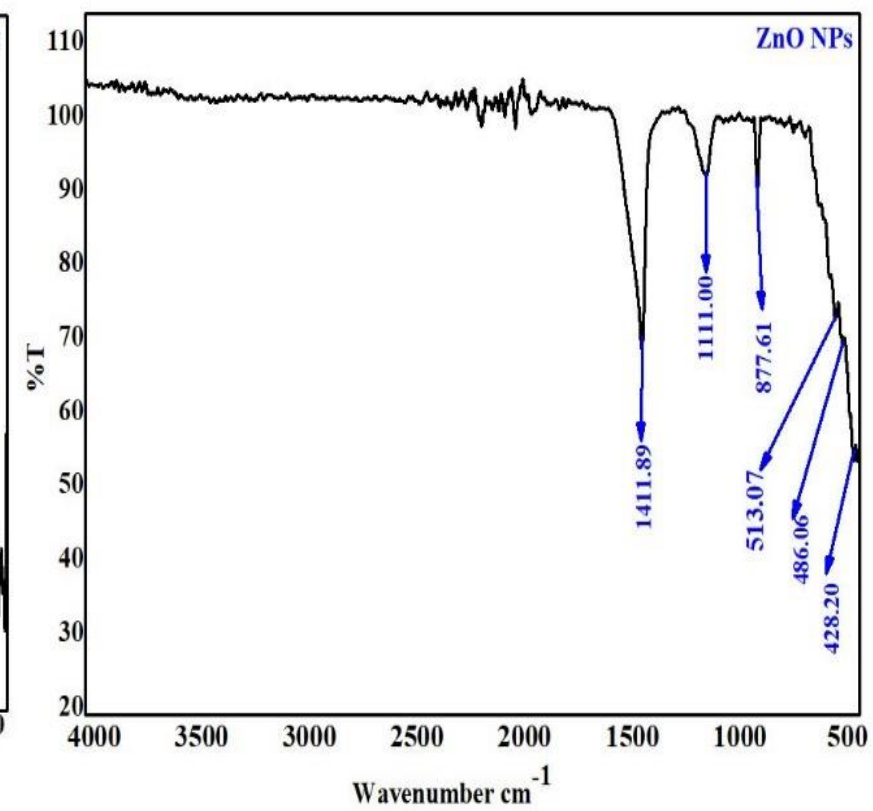

Fig. 3: FTIR analysis of plant extract and Gc-ZnO NPs

\section{XRD analysis}

The XRD spectrum of GC-ZnO NPs showed various Bragg's reflections, which corresponds to (100), (002), (101), (102), (110), (103), (200), (112), (201), (004), (202), (104), (203), (210), and (211) set of lattice planes respectively (Fig. 4). Based on these Bragg reflections, it revealed that the synthesized GC-
$\mathrm{ZnO}$ nanoparticles are essentially crystalline in nature. The mean crystalline size (D) of the particles were calculated by means of an X-ray line-broadening method using the Debye- Scherrer formula $(D=0.94 \lambda$ / B $\cos \theta$ ). The calculated crystalline size of the GC$\mathrm{ZnO}$ NPs is about $11.3 \mathrm{~nm}$ (International Centre for Diffraction Data (ICDD) number 01-078-4493.).

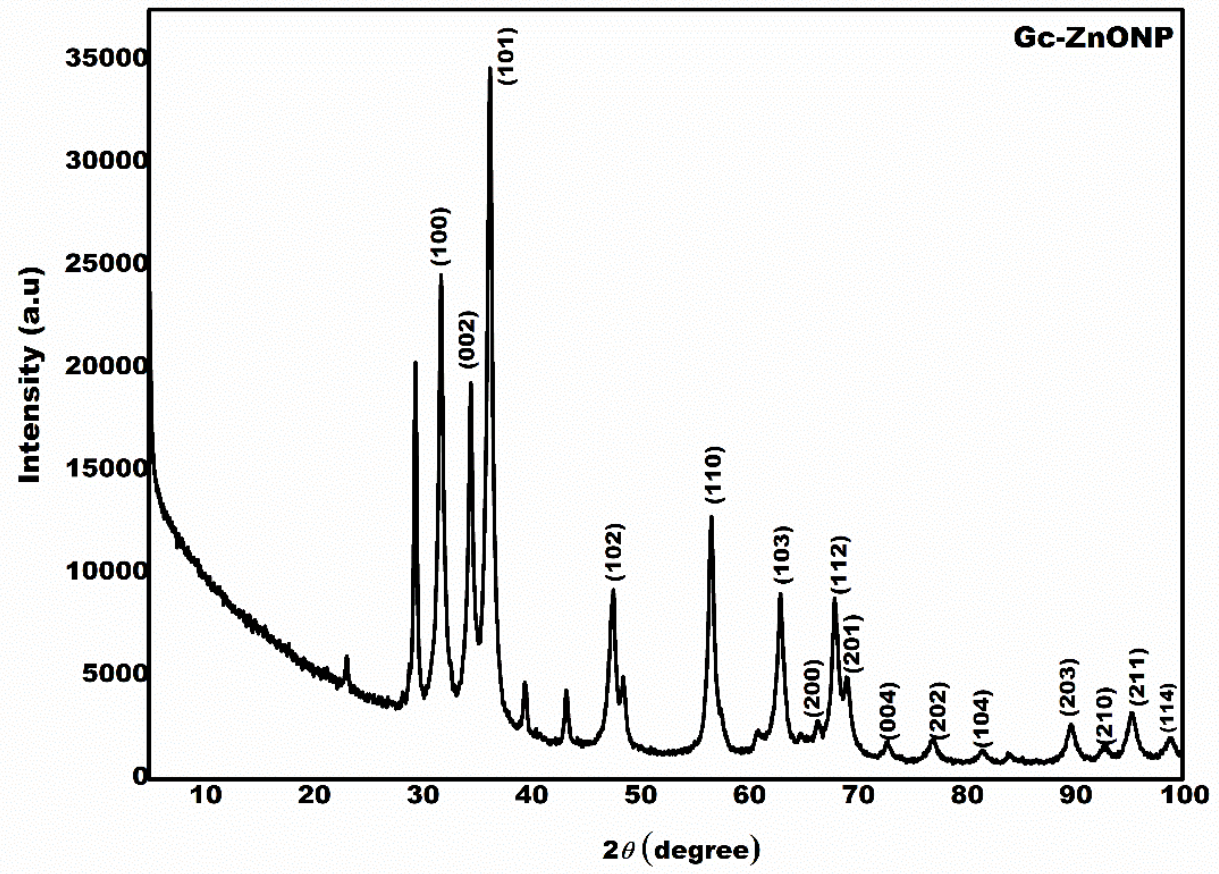

Fig. 4: XRD analysis of synthesized Gc-ZnO NP

\section{SEM and EDX analysis.}

The morphological dimensions of GC-ZnO NPs observed under SEM demonstrated that the particle size ranged between $10-40 \mathrm{~nm}$ with inter-particle distance. The shape of the GC-ZnO NPs were observed to be rod shaped or slightly pellet like. The EDX showed that the composition of $\mathrm{Zn}$ element in GC-ZnO NPs was $24.89 \%$ and $50.07 \%$ of O peaks clearly indicated that the product was of pure $\mathrm{ZnO}$ devoid of impurities (Fig. 5). 

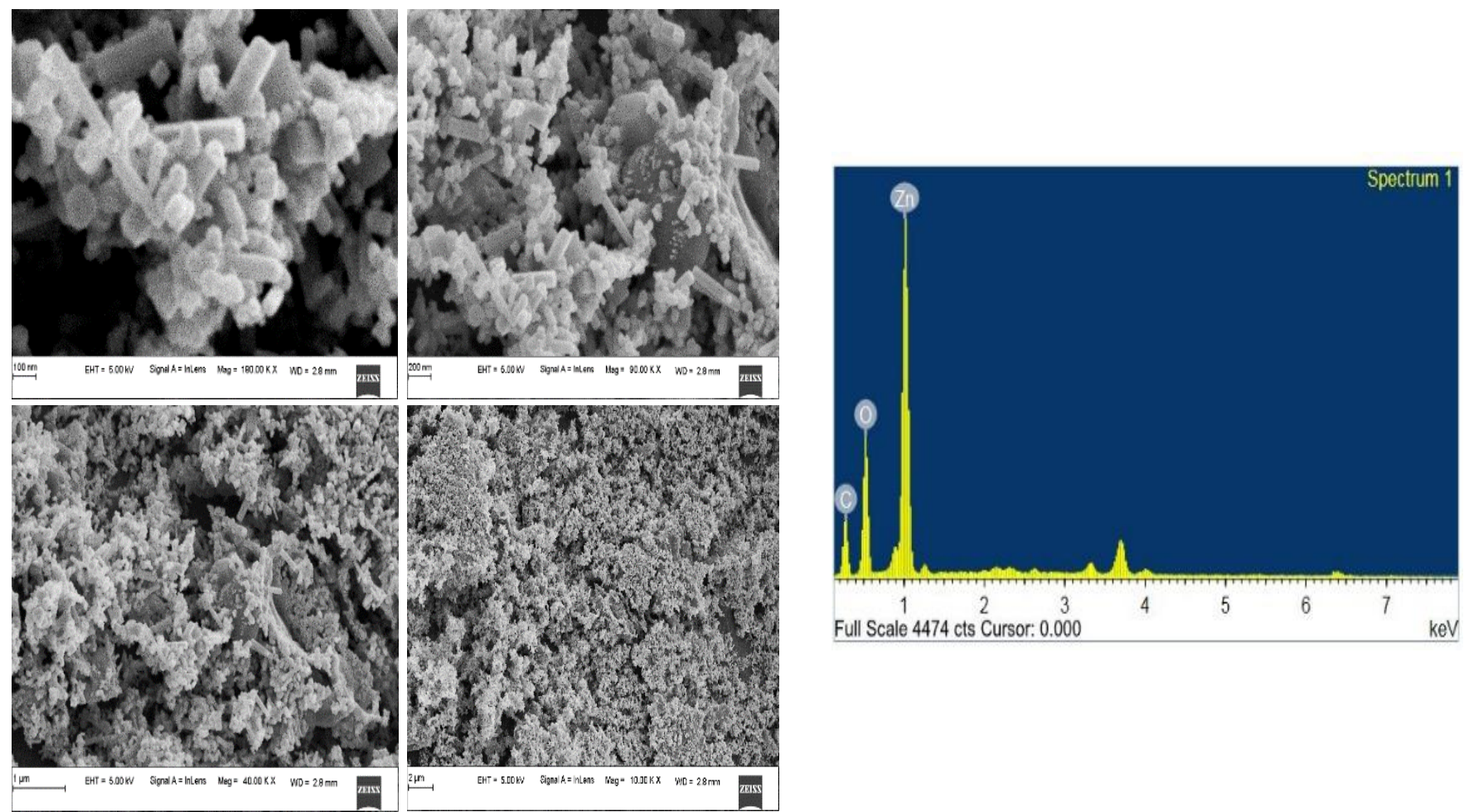

Fig. 5: SEM and EDAX analysis of synthesized Gc-ZnO NP

\section{HR-TEM and SAED pattern}

The morphological characters, size and size distribution of GC-ZnO NPs observed under TEM showed that the synthesized nanoparticles are in nanoscale range and uniformity. In addition, it shows
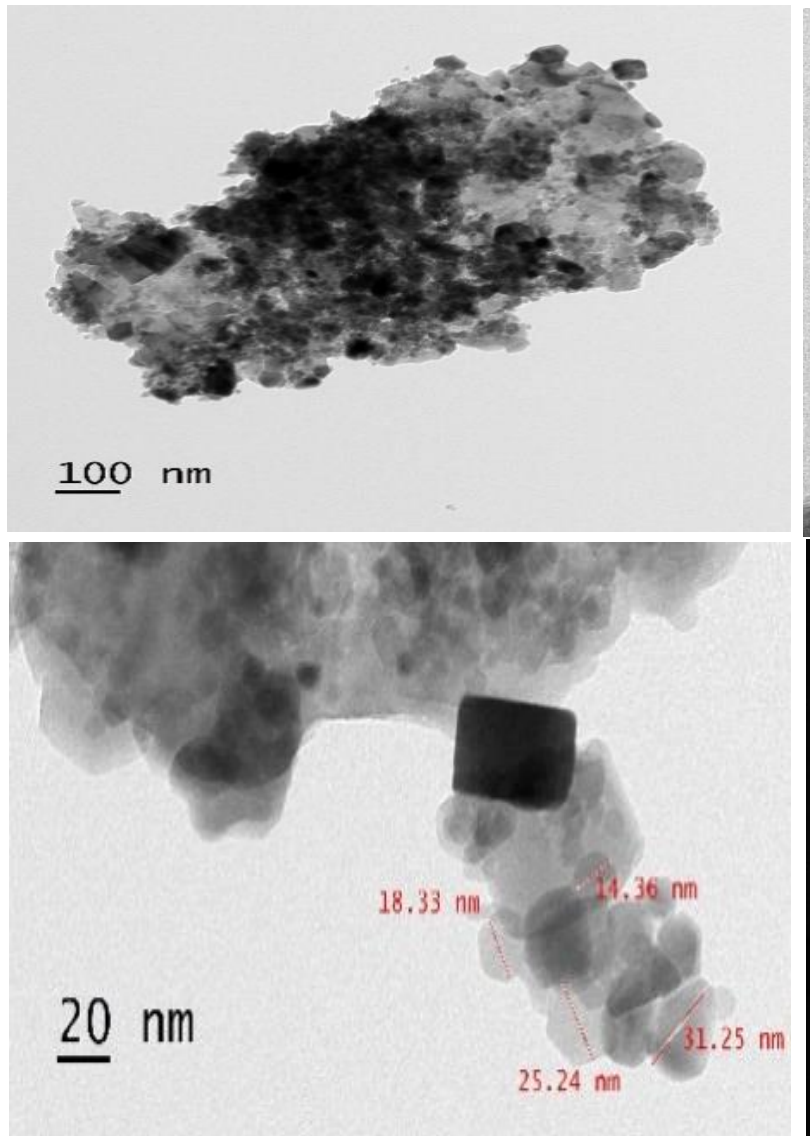

the size and shape of synthesized Nanoparticles ranges of 11-32 nm and mostly hexagonal forms. In addition, SAED revealed the ring patterns appeared with the light spots on the dark field. It reflects the crystalline structure of the ZnO NPs (Fig. 6).

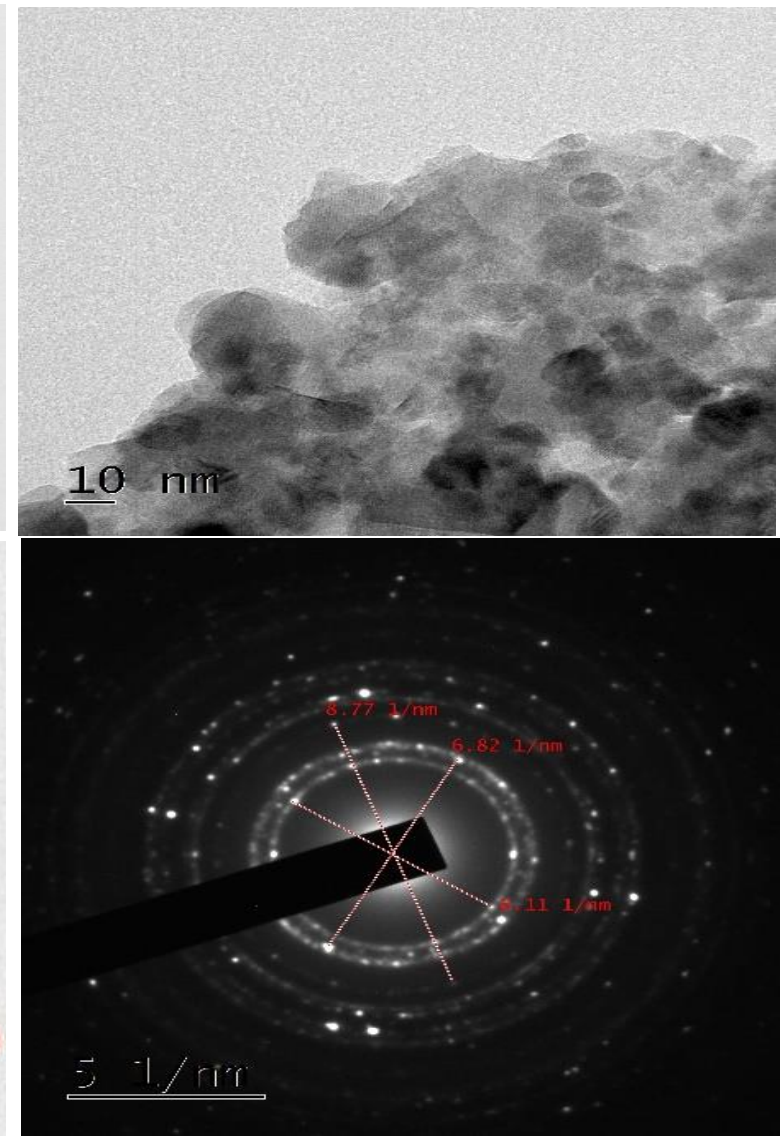

Fig. 6: TEM and SAED analysis of Gc- ZnO NP 


\section{Particle size distribution and Dynamic Light Scattering}

Average particle size of the GC-ZnO NPs using DLS method was found to be about $133.8 \mathrm{~nm}$ as shown in the figure $7 \mathrm{a}$, which is fairly higher than the X-ray diffraction method, which might be due to smaller nanoparticles agglomeration.

Zeta potential provides the zeta value which shows surface charge and stability of $\mathrm{ZnO}$ NPs (prepared using $G$ cambogia leaf extract) was $57.9 \mathrm{mV}$ (Figure 7b) demonstrating its stability.

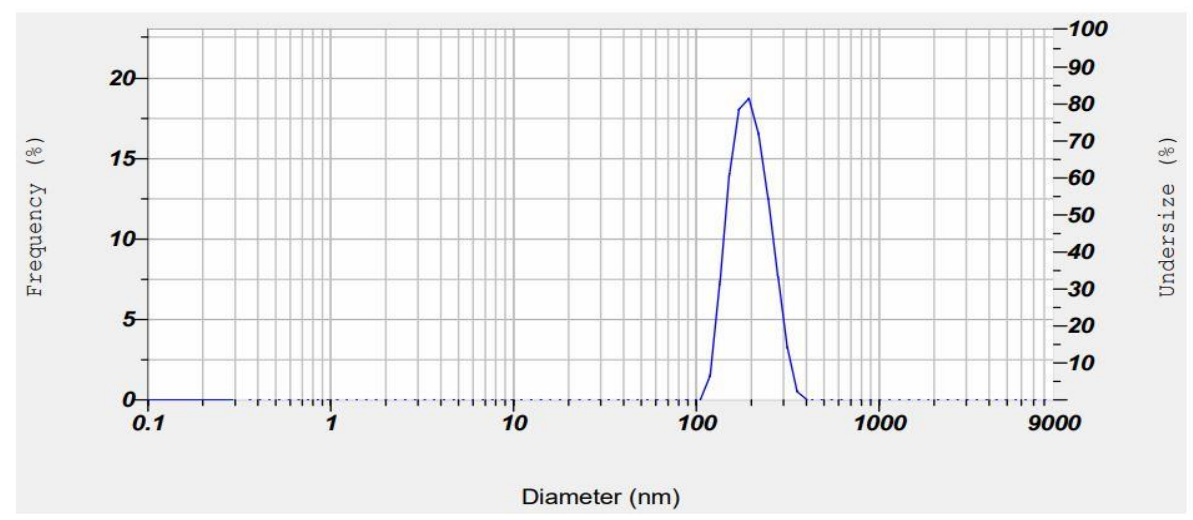

Fig. 7a: DLS analysis of Gc-ZnO NP

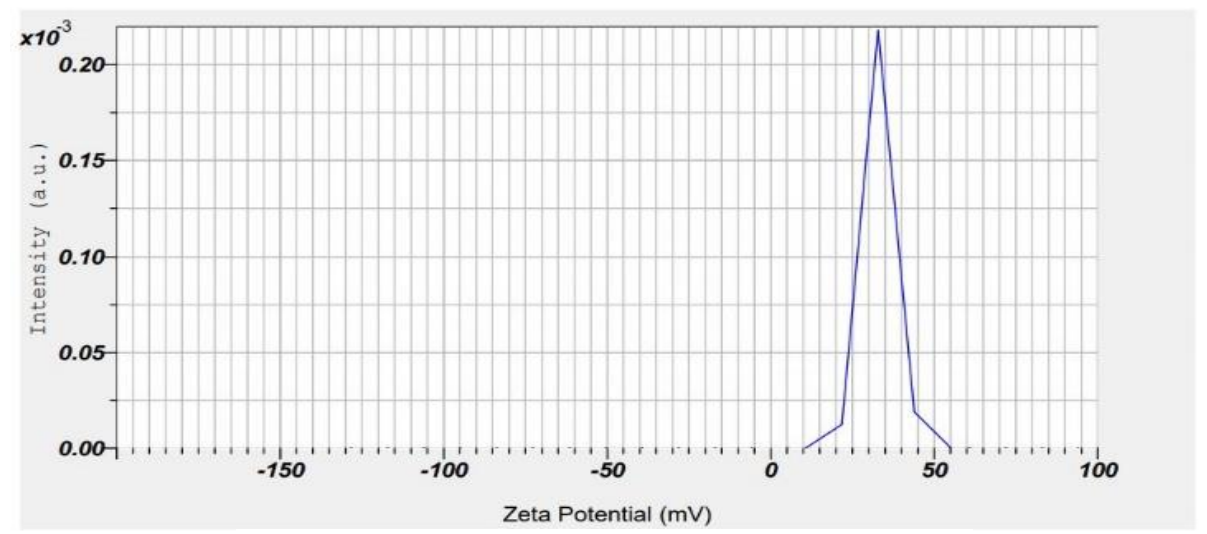

Fig. 7b: Zeta potential analysis of Gc-ZnO NP

\section{Antioxidant activity of plants}

FRAP assay

In the current study, Fig. 6 depicts antioxidant activity of standard ascorbic acid, aqueous leaf extract of GC and Gc-ZnO NPs at different concentrations in triplicates. The experimental data revealed that the aqueous crude extract of GC showed stronger FRAP activity at 100 concentration compared to Gc-ZnO NPs and standard ascorbic acid. While Gc-ZnO NPs showed almost similar result compared to standard ascorbic acid as the concentration is increased (Fig. 8).

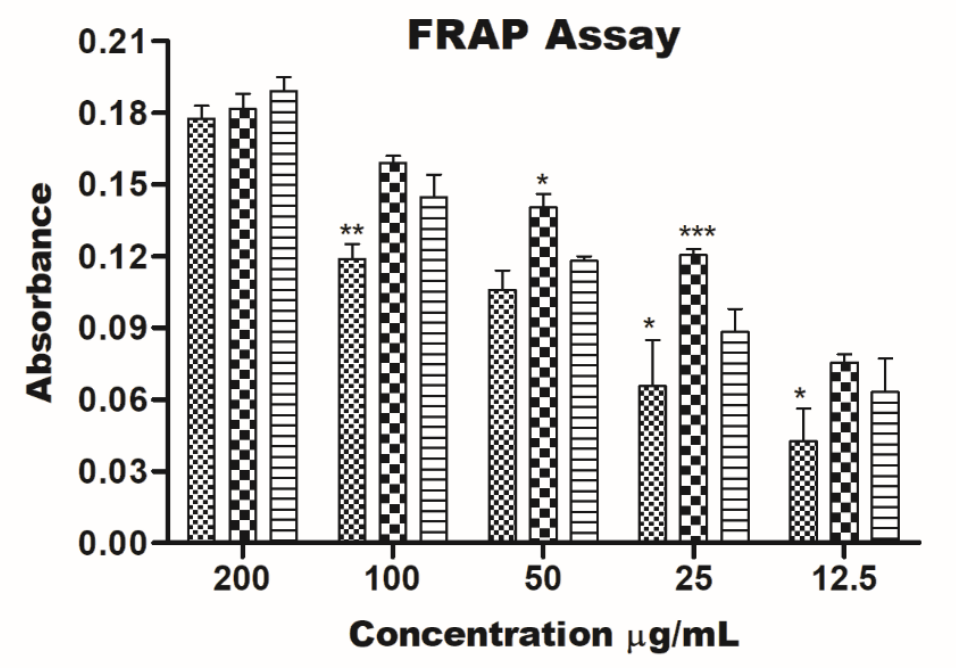

89 Gc-ZnONP $\mathrm{Q}$ GC extract

Fig. 8: FRAP activity of aqueous extract of GC and Gc-ZnO NP. Data is expressed as mean \pm SEM (n=3). Statistical significance was assessed using two way ANOVA $(* \mathrm{p}<0.05 ; * * \mathrm{p}<0.01 ; * * * \mathrm{p}<0.001)$ as compared to standard group. 


\section{PM assay}

In the current study, Phosphomolybdenum assay showed significantly higher result in both Gc-ZnO NPs and aqueous crude extract of GC and almost similar values compared to standard ascorbic acid (Fig. 9). During FRAP and PM assay, both the plant and Gc-ZnO NPs exhibited higher activity as the concentration is increased.

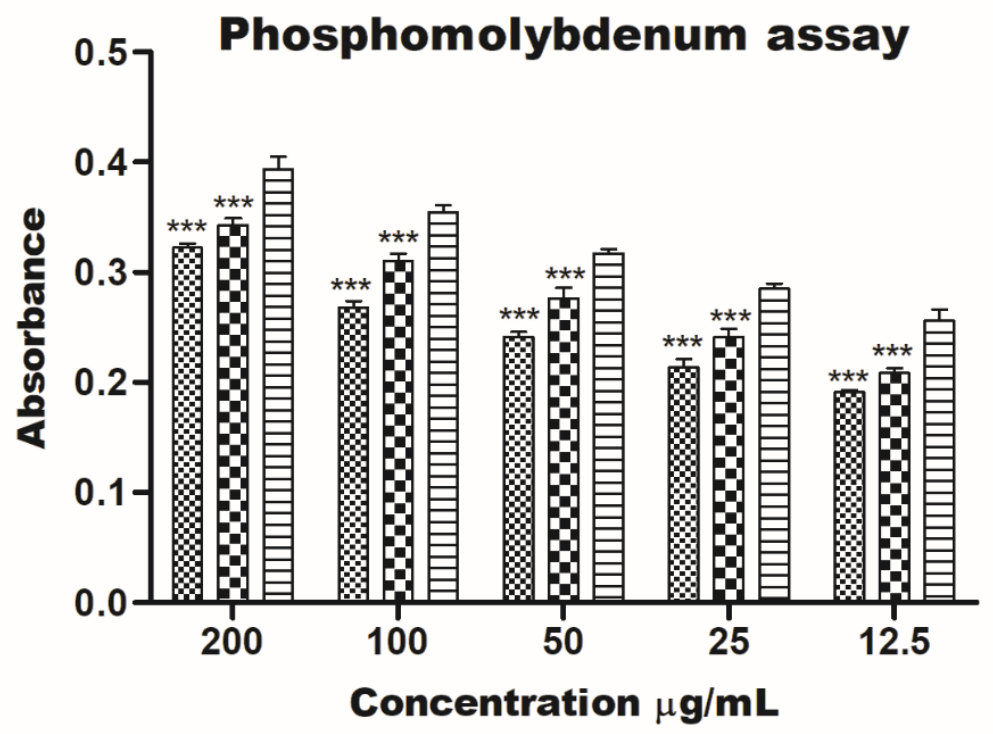

祭 Gc-ZnONP $\quad$ GC extract $\rightleftharpoons$ Ascorbic acid

Fig. 9: PM assay of aqueous extract of GC and Gc-ZnO NP. Data is expressed as mean \pm SEM ( $n=3$ ). Statistical significance was assessed using two way ANOVA $(* * * p<0.001)$ as compared to standard group.

\section{DPPH assay}

In the current study, the varied concentrations of Gc$\mathrm{ZnO}$ NPs and GC leaf extracts were subjected to 2diphenyl- 1picrylhydrazyl free radical scavenging assay. Ascorbic acid was used as a standard to compare the antioxidant capacity of the extract and synthesized nanoparticle. GC extract showed significant effect at 12.5 concentration compared to standard ascorbic acid and Gc-ZnO NPS. However,
Gc-ZnO NPs showed stronger antioxidant activity compared to GC extract as the concentration is increased (Fig. 10). When the antioxidant activities of both the plant and Gc-ZnO NPs were compared with ascorbic acid, $\mathrm{GC}$ showed the $\mathrm{IC}_{\mathbf{5 0}}$ value of 47.62 $\mu \mathrm{g} / \mathrm{mL}$ and $\mathrm{Gc}-\mathrm{ZnO}$ NPs showed $\mathrm{IC}_{50}$ value of 61.36 $\mu \mathrm{g} / \mathrm{mL}$ while ascorbic acid showed $\mathrm{IC}_{50}$ value of 68.85 with $\mathrm{R}^{2}$ value of $0.9722,0.9536$ and 0.9731 respectively.

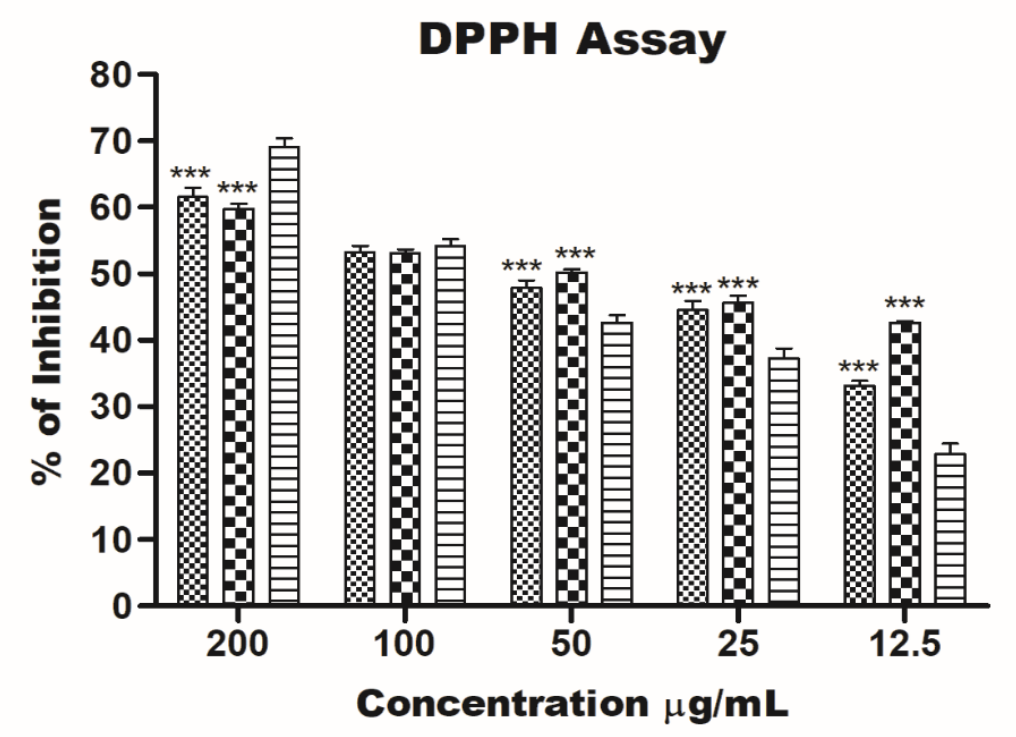

$\approx$ Gc-ZnONP $\quad$ GC extract $\Longrightarrow$ Ascorbic acid

Fig. 10: DPPH scavenging activity of aqueous extract of GC and Gc-ZnO NP. Each value is expressed as means \pm standard deviation. Concentration $(\mu \mathrm{g} / \mathrm{ml})$ taken on $\mathrm{x}$-axis and percentage inhibition taken on $\mathrm{y}$-axis. Statistical significance was assessed using two way ANOVA $(* * * p<0.001)$ as compared to standard group. 


\section{Cytotoxicity}

In the current study, the MTT and XTT assay were used to evaluate the influence of aqueous GC extract and Gc-ZnO NPs $(6.25-200 \mu \mathrm{M} ; 48 \mathrm{~h})$ treatment on the cell viability of two kidney cell lines, HEK293 human embryonic renal cells and A498 human renal carcinoma cells.

\section{MTT assay- HEK293}

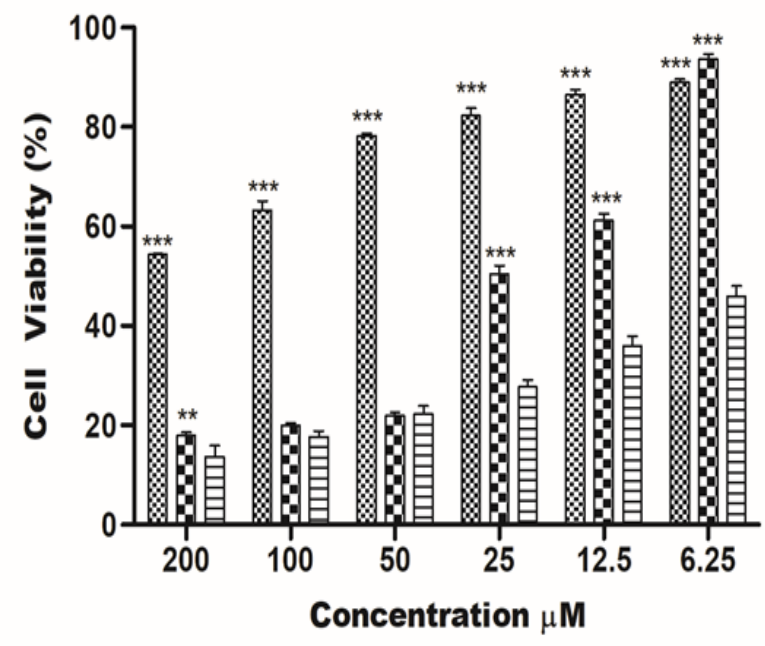

GC extract
Go-ZnONP
Cisplatin
At low concentration $(6.25 \mu \mathrm{g} / \mathrm{mL}), 15 \%$ MTT and XTT reduction was seen for both $\mathrm{GC}$ extract and $\mathrm{ZnO}$ NP. Whereas at high concentration $(200 \mu \mathrm{g} / \mathrm{mL})$, the percentage reduction was high at $65 \%$ and $80 \%$ (figure $11 \mathrm{a}$ and $\mathrm{b}$ ) for 48 hours respectively. These results suggest that the effect of GC and $\mathrm{ZnO} \mathrm{NP}$ are both time and dose dependent for decreasing percentage of MTT.

\section{MTT assay - A498}

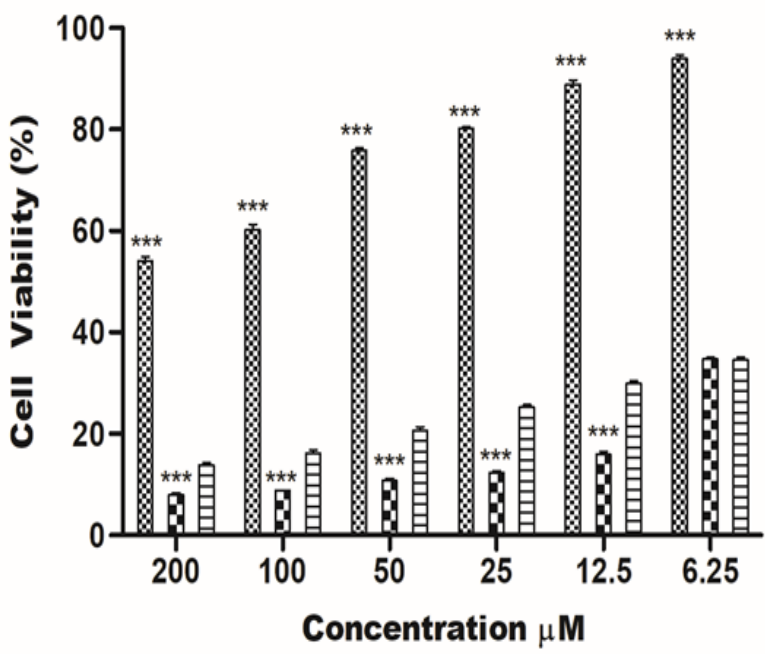

m GC extract $\mathbf{D}$ Gc-ZnONP $\boxminus$ Cisplatin

Fig. 11a: Cytotoxicity of aqueous extracts of GC and Gc-ZnO NP compared with standard drug on HEK-293 and A498 kidney cancer cell line (MTT assay). Data is expressed as mean \pm SEM $(n=3)$. Statistical significance was assessed using two way ANOVA in GraphPad Prism 5 Software $(* * * p<0.001)$ as compared to standard.
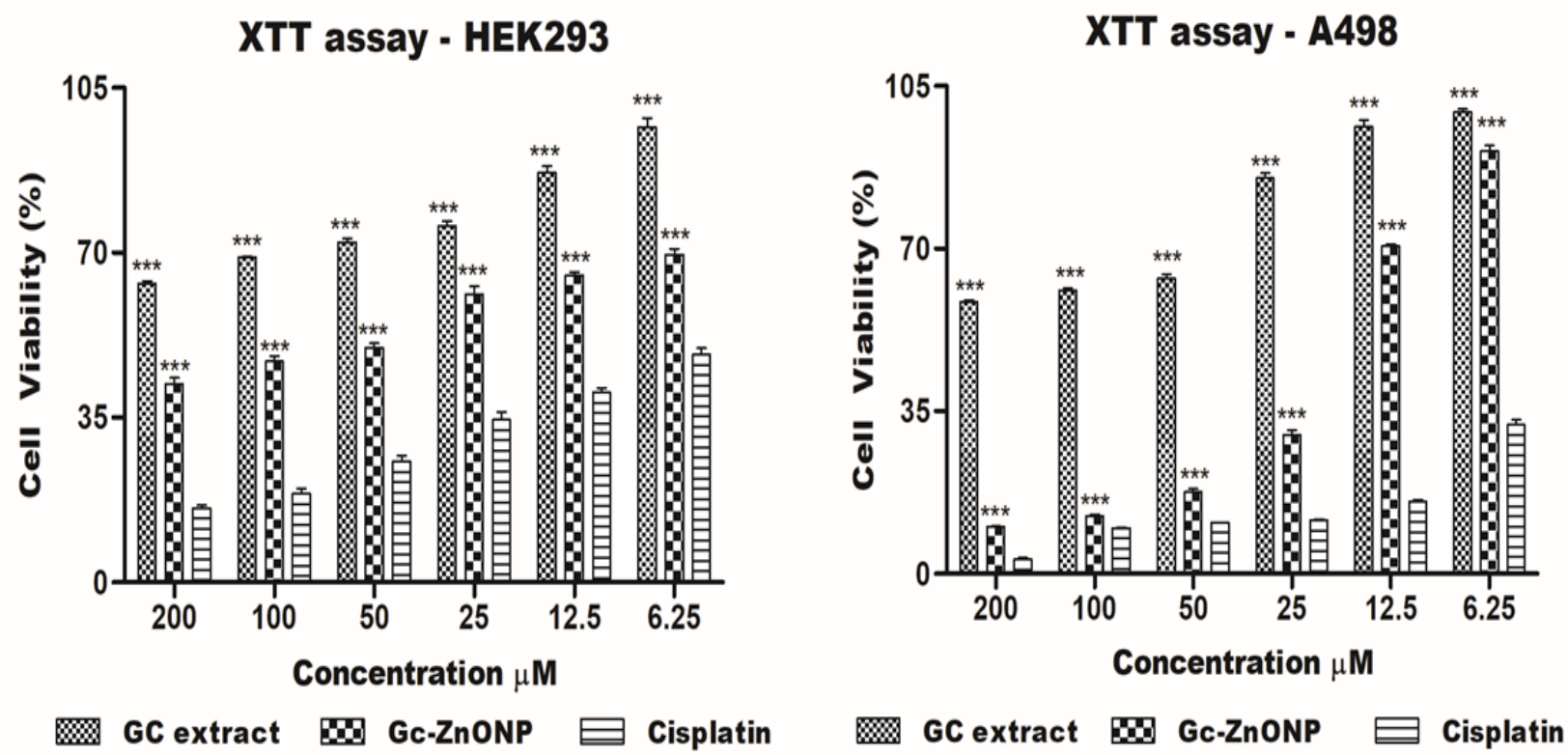

Fig. 11b: Cytotoxicity of aqueous extracts of GC and Gc-ZnO NP compared with standard drug on HEK-293 and A498 kidney cancer cell line (XTT assay). Data is expressed as mean \pm SEM $(n=3)$. Statistical significance was assessed using two way ANOVA in GraphPad Prism 5 Software $(* * * p<0.001)$ as compared to standard.

\section{MTT assay}

A498 cancer cell lines exposed to GC extract and obtained Gc-ZnO NPs results in mitochondrial damage or cellular death due to the fact of lesser particle size and more number of particles entered into the cells resulting in the formation of higher oxidative stress leading to cellular apoptosis. Morphological changes showing inhibition of A498 and HEK-293 cell line for $48 \mathrm{~h}$ is shown in figure $12 . \mathrm{IC}_{50}$ values and selective index of aqueous leaf extracts of GC, Gc$\mathrm{ZnO} \mathrm{NP}$ and Cisplatin on normal cell line and cancer cell line by MTT assay is shown in table 2 . 
MTT assay

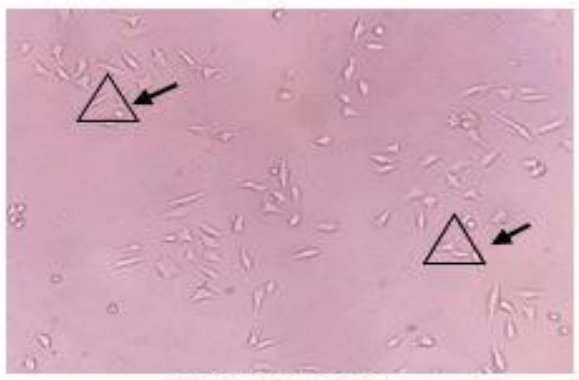

NC HEK293

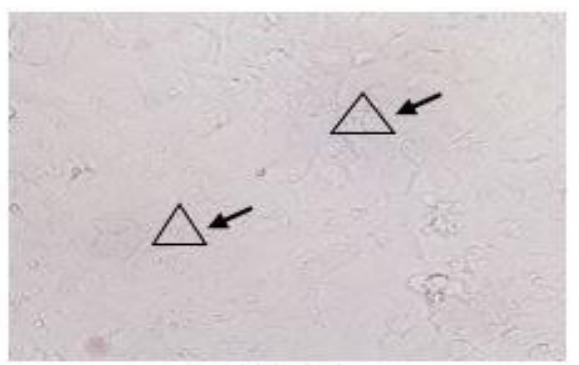

NC A498

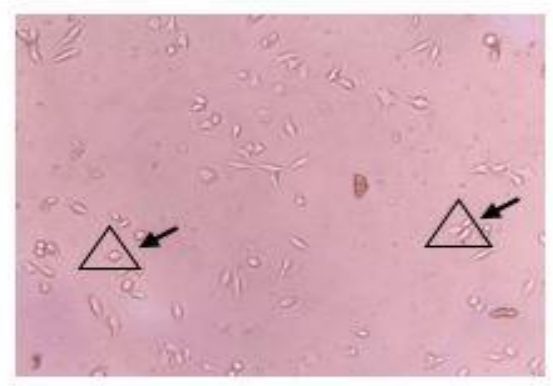

GC HEK 293

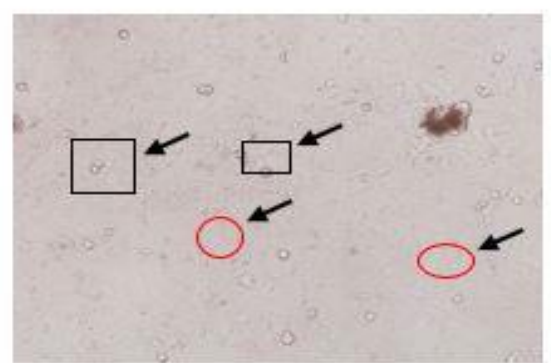

GC A498

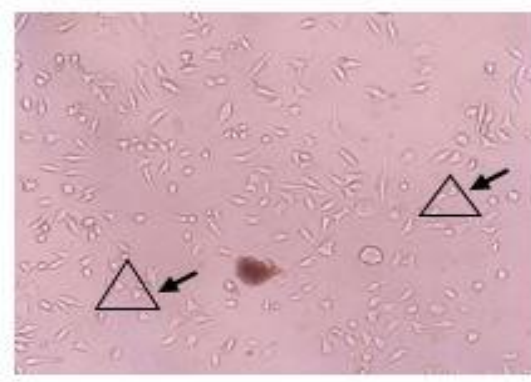

Gc-ZnONP HEK293

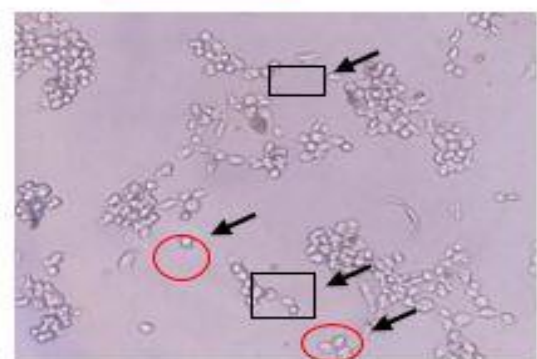

Gc-ZnONP A498

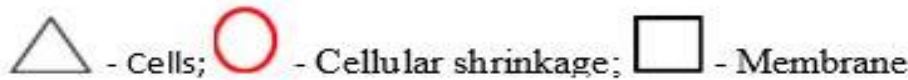

Fig. 12: Morphological changes in MTT assay showing inhibition of A498 and HEK-293 cell line for 48 h. (Magnification for A498 was 40X and HEK-293 was 20X).

\section{XTT assay}

Figure 13 shows the morphological changes and membrane blebbing with a magnification of $40 \mathrm{X}$ for A498 and 20X for HEK-293 indicating the inhibition of A498 and HEK-293 cell line for $48 \mathrm{~h}$. The reason for the cytotoxicity may be oxidative stress when the
$\mathrm{ZnO}$ NPs enter the cell leading to accumulate and create oxidative stress (ROS generation) in the cell. Cisplatin was used as a standard drug (fig. 14). IC $_{50}$ values and selective index of aqueous leaf extracts of $\mathrm{GC}, \mathrm{Gc}-\mathrm{ZnO} \mathrm{NP}$ and Cisplatin on normal cell line and cancer cell line by MTT assay and XTT assay is shown in table 1 and 2 respectively.

\section{XTT assay}

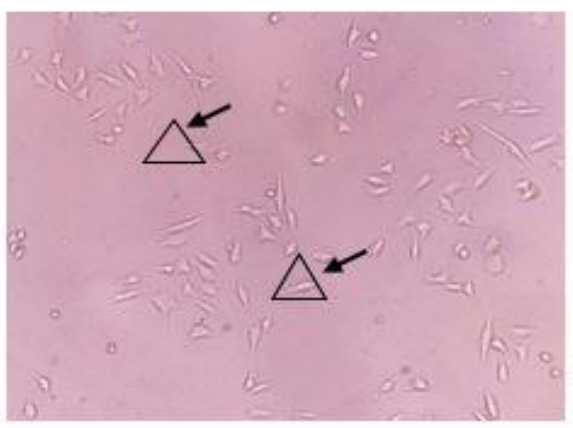

NC HEK293

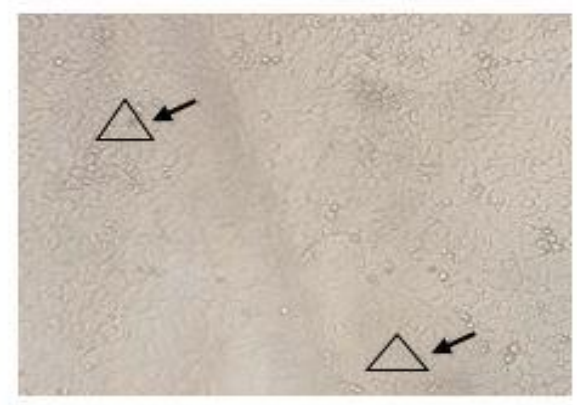

NC A498

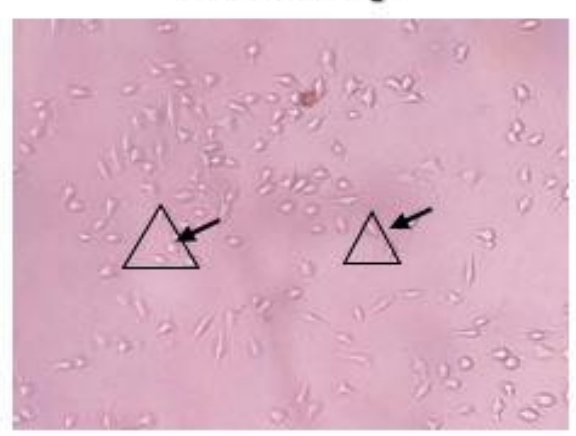

GC HEK293

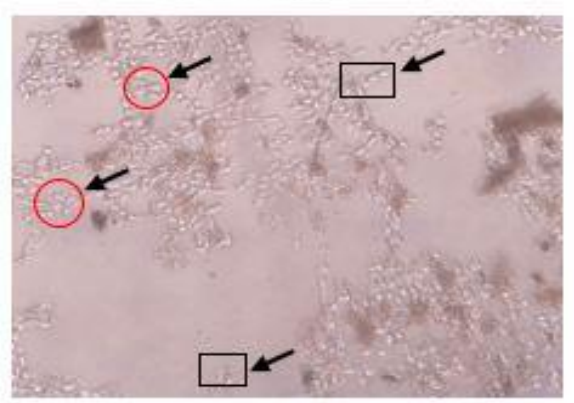

GC A498

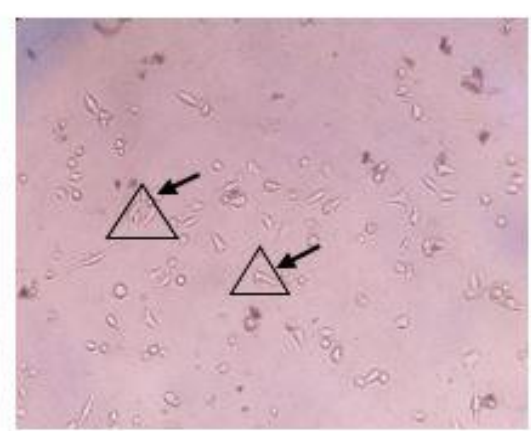

Gc-ZnONP HEK293

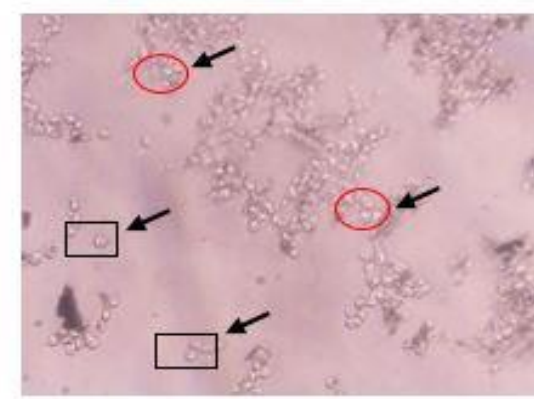

Gc-ZnONP A498

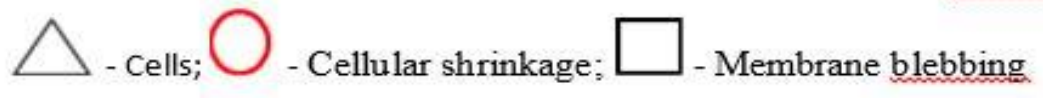

Fig. 13: Morphological changes in XTT assay showing inhibition of A498 and HEK-293 cell line for 48 h. (Magnification for A498 was 40X and HEK-293 was 20X). 


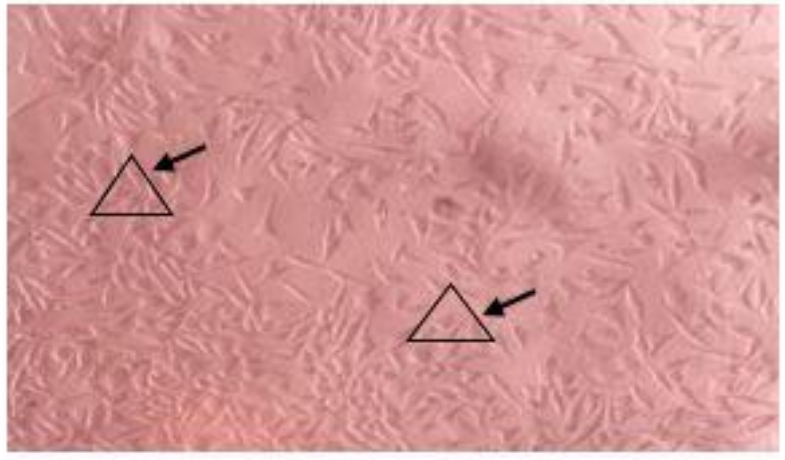

NC HEK293

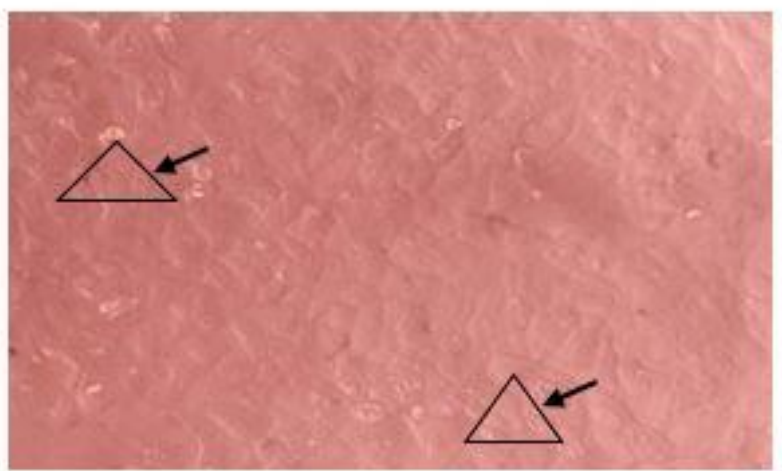

NC A498

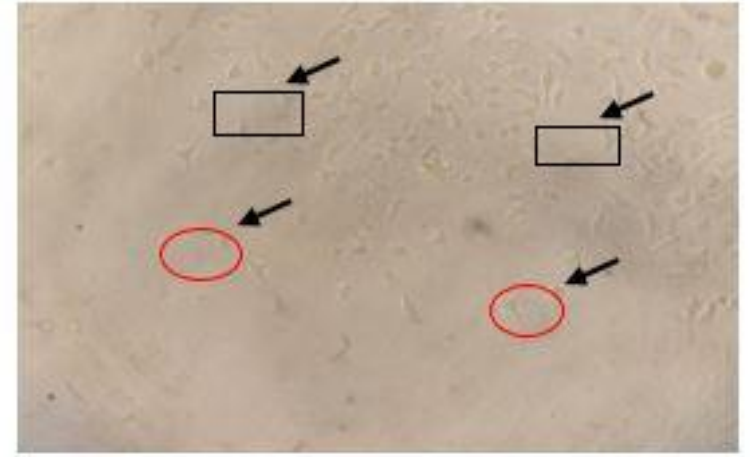

Cisplatin HEK293

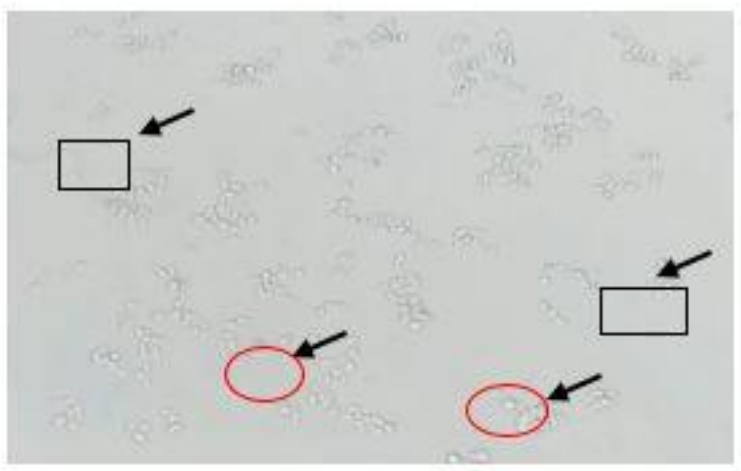

Cisplatin A498

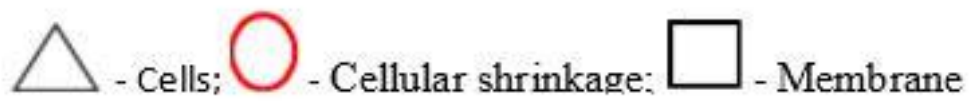

Fig. 14: Morphological changes of Standard drug cisplatin on HEK293 normal cell line and A498 kidney cancer cell lines. (Magnification for A498 was 20X).

Table 1: $\mathrm{IC}_{50}$ values and selective index of aqueous leaf extracts of $\mathrm{GC}, \mathrm{Gc}-\mathrm{ZnO} \mathrm{NP}$ and Cisplatin on two renal cell lines by MTT

\begin{tabular}{|c|c|c|c|c|}
\hline Compound & Concentration & HEK293 & A498 & Selectivity index (SI) \\
\hline GC extract & $\mathrm{IC}_{50}(\mathrm{mg} / \mathrm{mL})$ & 488.2 & 225.4 & 2.17 \\
\hline Gc-ZnO NP & $\mathrm{IC}_{50}(\mathrm{mg} / \mathrm{mL})$ & 24.08 & 1.828 & 13.17 \\
\hline Cisplatin & $\mathrm{IC}_{50}(\mathrm{mg} / \mathrm{mL})$ & 4.108 & 1.071 & 3.84 \\
\hline
\end{tabular}

Table 2: $\mathrm{IC}_{50}$ values and selective index of aqueous leaf extracts of $\mathrm{GC}, \mathrm{Gc}-\mathrm{ZnO} \mathrm{NP}$ and Cisplatin on two renal cell lines by XTT

\begin{tabular}{|c|c|c|c|c|}
\hline Compound & Concentration & HEK293 & A498 & Selectivity index (SI) \\
\hline GC extract & $\mathrm{IC}_{50}(\mathrm{mg} / \mathrm{mL})$ & 452.1 & 220 & 2.05 \\
\hline Gc-ZnO NP & $\mathrm{IC}_{50}(\mathrm{mg} / \mathrm{mL})$ & 70.98 & 18.86 & 3.764 \\
\hline Cisplatin & $\mathrm{IC}_{50}(\mathrm{mg} / \mathrm{mL})$ & 5.631 & 1.668 & 3.376 \\
\hline
\end{tabular}

HEK293- Human embryonic kidney cells

A498- Human kidney cancer cell

SI values $>2$ was considered as high selectivity.

\section{DISCUSSION}

With the growing interest to limit the use of hazardous nanoparticles, the development of biological, biomimetic and biochemical approaches for the synthesis of nanoparticles is desirable. Green method of nanoparticles synthesis is more advantageous than physico-chemical methods because of its non-toxic and environmental-friendly nature. The synthesis of $\mathrm{Gc}-\mathrm{ZnO} \mathrm{NPs}$ in the present study was established through UV-Vis spectroscopy, XRD, FTIR, SEM, EDAX, TEM, SAED, DLS and zeta potential analysis. It is reported that UV-Vis spectroscopy could be used to determine the size and shape of nanoparticles in aqueous solution (19). In the present study, the UVVis absorption spectrum of Gc-ZnO NPs at higher metal concentration $(75 \mathrm{mM}$ and $100 \mathrm{mM})$ exhibited broad absorption spectra at $277 \mathrm{~nm}$, however, the synthesized Gc-ZnO NPs at $50 \mathrm{mM}$ showed strong absorption peak at $266 \mathrm{~nm}$ due to its surface plasmon resonance (fig. 2). The increase in the absorbance peak of GC-ZnO NPs may be due to the functional molecules present in the leaf extract. The size and shape of nanoparticles, dielectric constant of the medium and surface adsorbed species determine the spectral position of plasmon band absorption as well 
as its width (19). In the present study, FTIR spectroscopic analysis was used to know the phytochemicals present in plant extracts responsible for the reduction of $\mathrm{Zn}^{2+}$ ions and stabilization of $\mathrm{ZnO}$ NPs. Fig. 3 shows the multifunctional behaviour of phytochemicals present in G. cambogia before and after synthesis of $\mathrm{ZnO}$ NPs. The functional groups such as $-\mathrm{C}-\mathrm{O}-,-\mathrm{CO}-\mathrm{C}-$, and $-\mathrm{C}=\mathrm{C}-$ are derived from heterocyclic compounds and the amide bonds derived from the proteins present in the leaf extract of G. cambogia (Gummi-gutta) act as capping ligand which give stability to Gc-ZnO NPs. These results are consistent with the previous findings who reported that the stability of $\mathrm{ZnO} \mathrm{Nps}$ is due to capping agent of plant extract involved in synthesis (20-22).

In addition, the study of physico-chemical parameters such as concentration, volume, and temperature have a direct impact in biosynthesis process of $\mathrm{ZnO}$ nanoparticles and changing in any of the factors causing the change in synthesis process. (14). X-ray powder diffraction (XRD) was used to analyse the structural properties of the ZnO NPs and to identify the phase and crystallinity of Gc-ZnO NPs. The diffraction peaks corresponding to synthesized $\mathrm{ZnO}$ NPs match well with the standard $\mathrm{ZnO}$ hexagonal wurtzite structure (figure 4). No extra diffraction peaks corresponding to impurities were detected, indicating that relatively pure $\mathrm{ZnO}$ NPs was obtained. The powder XRD pattern indicates the hexagonal and crystalline nature of optimised $\mathrm{ZnO}$ NPs. $\mathrm{ZnO}$ hexagonal phase (wurtzite structure) compared with International Centre for Diffraction Data (ICDD) number 01-078-4493 confirms the XRD peaks obtained in the present study. These results were well supported by the XRD pattern of $\mathrm{ZnO}$ NPs reported earlier (7).

SEM analysis was typically conducted to mark the surface morphology. Figure 5 includes 5 SEM image of $\mathrm{ZnO}$ NPs at different magnification ranges. GC$\mathrm{ZnO}$ NPs showed slightly pellet like or rod-shaped nanoparticle with a surface diameter range of 10-40 $\mathrm{nm}$, which might be due to the orientation, interaction, and fusion of nanoparticles. Which lead to agglomeration that serves as a crystal seed to grow the pellet-like structure. The development of uniform structure is because of homogeneous nucleation with constant and prolonged calculations at a higher temperature (23). The elemental composition and purity of synthesized green nanoparticles were determined by energy dispersive8X-ray spectra (fig. 5). The EDX spectrum reflects the presence of $\mathrm{Zn}$ with atomic percent of $24.89 \%$ and $50.07 \%$ of $O$ peaks clearly indicated that the product was of pure $\mathrm{ZnO}$, devoid of impurities. Other weaker signals of $\mathrm{K}, \mathrm{L}$ and $\mathrm{O}$ are owing to use precursor for the synthesis of nanoparticles. The size of Gc-ZnO NPs in this study corroborates with findings of Malaikozhundan et al.,
(2017), who reported that the size of ZnO NPs were between 30-40 $\mathrm{nm}$ (19).

The ZnO NPs morphology was analysed by transmission electron microscopy (TEM), which provides a clear understanding of the size, size distribution and morphological characters of Nanoparticles. TEM provide high spatial resolution images. Nanoparticles were well dispersed and encapsulated by extract was clearly observed as in the image. Figure 6 shows the ZnO NPs have hexagonal shape in the range of 11-32 nm. Crystalline structure of nanoparticle was confirmed by SAED patterns. The particle size determined from the TEM analysis is in good agreement with that of the XRD analysis. These results were consistent with the previously reported study (24). DLS method was used to study the average size of the particles (fig. 7a). The size distribution of the synthesized zinc oxide nanoparticles, their surface charge along with the stability was determined using a particle size analyser (fig. 7b).

As health-related risks are increasing at an alarming rate, evaluation of plant-derived antioxidants is of immense importance in today's context. Many bioactive components like phenols and flavonoids acts as sources of antioxidants and perform scavenging activity (16). In order to obtain the complete potential of antioxidants from any source, it is wise to utilise different assays while estimating the total antioxidant activity (25). In the present study, the antioxidant activity of synthesized $\mathrm{ZnO}$ NPs and aqueous leaf extract of G. cambogia was determined by using FRAP, PM and DPPH free radical assay. In FRAP assay, the ability of GC extract to reduce $\mathrm{Fe}^{3+}$ to $\mathrm{Fe}^{2+}$ was significantly higher than that of ascorbic acid at $25 \mu \mathrm{g} / \mathrm{mL}$ and Gc-ZnO NPs extract at lower concentration, however, as the concentration increased, even Gc-ZnO NPs showed significant FRAP activity at $100 \mu \mathrm{g} / \mathrm{mL}$ (figure 8). Phosphomolybdenum method was also selected to analyse the total antioxidant activity of the GC extract, $\mathrm{Gc}-\mathrm{ZnO}$ NPs and ascorbic acid. It is a colorimetric method, which helps in measuring the reduction of Phosphate-Mo (VI) to Phosphate-Mo (V) by the sample and eventually development of a bluish green coloured Phosphate-Mo (V) complex (26). Both GC and $\mathrm{Gc}-\mathrm{ZnO}$ NPs showed significant antioxidant property as the concentration is increased (fig. 9). DPPH is a stable compound, which can be reduced by accepting the hydrogen or electrons and has widely been used to evaluate the antioxidant activity. The lower $\mathrm{IC}_{50}$ value indicates a stronger ability of the extract to act as a DPPH scavenger, while the higher $\mathrm{IC}_{50}$ value indicates a lower scavenging activity. The effect of different concentrations of Gc-ZnO NPs on DPPH radical antioxidant activity is shown in figure 10. Our results revealed that the aqueous leaf extract and synthesized Gc-ZnO NPs are free radical scavengers. Moreover, at higher concentration, the 
Gc-ZnO NPs exhibited more scavenging activity of DPPH than GC extract. The DPPH activity of the Gc$\mathrm{ZnO}$ NPs and leaf extract was found to increase in a dose dependent manner (27). The difference in the $\mathrm{IC}_{50}$ value and potential DPPH radical scavenging activity observed in this study may be due to the phytochemical components present in the extracts. Our observation is in agreement with the previous report (28).

Plant extracts with antioxidants are the best sources to evaluate the anticancer activity with least or no side effects for safe diagnosis. It helps in identifying the deep-rooted toxicity of the plant and the effects of critical overdose. It could also help in screening possible cytotoxic properties of GC and Gc-ZnO NPs. MTT is one of the most commonly used in vitro model system to evaluate the cytotoxic effects of many toxic substances and plant extracts against cancer cell lines. XTT assay was used to determine cell viability using the calorimetric method. XTT assay is a modified assay of MTT viability tested by the conversion of XTT into XTT formazan through the mitochondrial enzyme. Like MTT assay, the XTT assay was also time- and dose-dependent (17).

Both MTT and XTT assay revealed that the viability of A498 cells decreases with increase in concentration of the GC extract and Gc-ZnO NPs. Only viable cells have the ability to reduce MTT tetrazolium and XTT into a coloured formazan product. The cytotoxic activity was expressed as percentage of cell viability in Hek-293 and A-498 cell lines when compared with the control and both the plant extract as well as Gc$\mathrm{ZnO}$ NPs revealed more cytotoxicity towards cancer cell line A498. Concentration in the range of 6.25 -200 $\mu \mathrm{g} / \mathrm{ml}$ and $6.25-200 \mu \mathrm{M}$ for GC extract, Gc-ZnO NPs and Cisplatin (control) respectively were used for the study. Both plant extract and Gc-ZnO NPs showed no cytotoxic effect towards non-cancerous HEK-293 cell line. To be precise, in both MTT and XTT assay, GC extract did not show significant cytotoxic effects in HEK-293 cells but, in A498 cells a slight decrease in cell viability was observed. However, Gc-ZnO NPs $(6.25 \mu \mathrm{M})$ did not show cytotoxicity in HEK-29. However, in A498 cells, a remarkable downfall in cell viability was observed (Fig. 11a and b). The effect produced by the extracts is comparable to that of the standard drug cisplatin, which is commonly used in the treatment of renal carcinoma. The results exposed morphological changes and cellular shrinkage resulting in cell death caused by the extracts in the renal cancer cell lines (Fig. 12 and 13). The survivability of cells to the leaf extract of GC, GcZnONPs and Cisplatin was characterized by $\mathrm{IC}_{\mathbf{5 0}}$ value using both MTT and XTT assay (Table 1 and 2). In vitro growth inhibition effects were observed in the kidney cancer cell line (A498), while there was no effect on the growth of normal cells (HEK-293). Such selective effects were incubation time and concentration dependent. All the extracts were evaluated in triplicates with respect to concentration $(6.25,12.5,25,50,100,200 \mu \mathrm{g} / \mathrm{ml})$ by serial dilution. Higher concentrations, $200 \mu \mathrm{g} / \mathrm{ml}$ of both plant extracts were the most effective in producing growth inhibition. However, the pure standard Cisplatin drug showed significant inhibition on the cancer cell lines (37). The results confirmed the differential effect induced by the GC extract, Gc-ZnO NPs and cisplatin in A498 and HEK-293 cell lines.

When the concentration of the extract and Gc-ZnO NPs was increased, it was observed that there was rapid decrease in cell-cell contact and cell proliferation. It indicates that the cytotoxic effect gradually increases with increase in the concentration. SI values were also calculated for both the extracts on renal cell lines and compared to those calculated for cisplatin (Table 1 and 2). The SI values calculated for aqueous extract of GC was 2.17 (MTT assay) and 2.05 (XTT assay) while Gc-ZnO NPs was 13.17 (MTT assay) and 3.764 (XTT assay). The SI values calculated for Cisplatin for renal cell line was low (3.84 for MTT assay and 3.376 for XTT assay), indicating the superiority of Gc-ZnO NPs on the cancer cell line compared to GC extract and Cisplatin. Based on the low $\mathrm{IC}_{50}$ value and high SI values for both extract in these cells suggest Gc-ZnO NP and GC extract as a promising therapeutic candidate in patients with renal cancers. Higher the SI value, the more selective it is and SI values less than 2 indicate general toxicity (18). Gleaned from the results, it can be inferred that compared to Cisplatin, a common chemotherapy drug, GC and Gc-ZnO NPs are better candidates for growth suppression of renal cell lines with SI values $>2$.

\section{CONCLUSION}

It was observed that the aqueous extract of GC containing a wide variety of bioactive components and Gc-ZnO NPs possess strong antioxidant capacity based on the experiments performed which gives a scientific evidence to conduct further studies. The present in-vitro anticancer activity exposed the abilities of GC and Gc-ZnO NPs extract as a curative agent for cancer treatment as it not only has a highly potent activity at 200 concentrations but also exhibits a high degree of selectivity in kidney cancer cells. This activity may be due to the presence of bioactive compounds and antioxidants present in GC extract, which also acted as capping agent for Gc-ZnO NPs. Our results reveal that aqueous leaf extract of GC and Gc-ZnO NPs displays cytotoxic effects on A498 human renal carcinoma cells at $200 \mu \mathrm{M}$ respectively, it may be safely used against kidney cancer since, at this concentration; no significant effect was observed in normal renal cells. Our results suggest GC and Gc$\mathrm{ZnO} \mathrm{NP}$ extracts are attractive option for pharmaceutical companies as a potential agent for the management of human cancer. However, further 
studies to isolate the secondary metabolites responsible for these activities and also which are involved in the synthesis of nanoparticles by acting as capping and stabilizing agents are underway to explore their molecular mechanism.

\section{ACKNOWLEDGMENTS}

The authors are grateful to DST-SAIF Cochin, DSTPURSE Phase-II program, USIC and SAIF Karnataka University Dharwad, CARRT and DST-PURSE Mangalore University for Characterisation techniques. Authors would also like to thank the Principal, St. Aloysius College (Autonomous), Mangalore, and Prof. B. K. Sarojini, Coordinator of Biochemistry Course, Mangalore University, Mangalagangothri, for providing the laboratory facility to carry out the research.

\section{CONFLICT OF INTEREST}

The authors declare that they have no conflict of interest for this study.

\section{REFERENCES}

1. Liu, R., Pei, Q., Shou, T., Zhang, W., Hu, J., Li, W. Apoptotic effect of green synthesized gold nanoparticles from Curcuma wenyujin extract against human renal cell carcinoma A498 cells. International Journal of Nanomedicine. 2019; 14: 4091.

2. Rutz, J., Maxeiner, S., Juengel, E., Bernd, A., Kippenberger, S., Zöller, N., et al. Growth and proliferation of renal cell carcinoma cells is blocked by low curcumin concentrations combined with visible light irradiation. International Journal of Molecular Sciences. 2019 Jan; 20(6): 1464.

3. Xu, M., Wang, Y., Zhou, L. N., Xu, L. J., Jin, Z. C., Yang, D. R., et al. The therapeutic value of SC66 in human renal cell carcinoma cells. Cell Death \& Disease. 2020 May 11; 11(5): $1-1$.

4. Swiatek, M., Jancewicz, I., Kluebsoongnoen, J., Zub, R., Maassen, A., Kubala, S., et al. Various forms of HIF-1 $\alpha$ protein characterize the clear cell renal cell carcinoma cell lines. IUBMB life. 2020 Jun; 72(6): 1220-1232.

5. Wang, X., Liu, J., Xie, Z., Rao, J., Xu, G., Huang, K., et al. Chlorogenic acid inhibits proliferation and induces apoptosis in A498 human kidney cancer cells via inactivating PI 3K/Akt/mTOR signalling pathway. Journal of Pharmacy and Pharmacology. 2019; 71(7): 1100-1109.

6. Al-Ajmi, M. F., Hussain, A., Alsharaeh, E., Ahmed, F., Amir, S., Anwar, M. S., et al. Green synthesis of zinc oxide nanoparticles using Alstonia macrophylla leaf extract and their in-vitro anticancer activity. Science of Advanced Materials. 2018 Mar 1; 10(3): 349-355.

7. Selim, Y. A., Azb, M. A., Ragab, I., Abd El-Azim, M. H. Green synthesis of zinc oxide nanoparticles using aqueous extract of Deverra tortuosa and their cytotoxic activities. Scientific Reports. 2020 Feb 26; 10(1): 1-9.

8. Seethapathy, G. S., Tadesse, M., Urumarudappa, S. K., Gunaga, S. V., Vasudeva, R., Malterud, K. E., et al. Authentication of Garcinia fruits and food supplements using DNA barcoding and NMR spectroscopy. Scientific Reports. 2018 Jul 12; 8(1): 1-2.

9. Jayakar, V., Lokapur, V., Shantaram, M. Identification of the volatile bioactive compounds by GC-MS analysis from the leaf extracts of Garcinia cambogia and Garcinia indica. Medicinal Plants-International Journal of Phytomedicines and Related Industries. 2020; 12(4): 580-590.

10. Banu, S., Ramakrishnaiah, T. N. Screening of Garcinia cambogia for in-vitro anti-cancerous activity against colon adenocarcinoma (Caco-2) cell line. Res. J. Pharmacognosy and Phytochem. 2018 Oct 31; 10(4): 272-276.
11. Hart, C., Cock, I. E. An examination of the antimicrobial and anticancer properties of Garcinia cambogia fruit pericarp extracts. Biology, Engineering, Medicine and Science Reports. 2016 Jul 1; 2(2): 55-63.

12. Espirito Santo, B. L., Santana, L. F., Kato Junior, W. H., de Araújo, F. D., Bogo, D., Freitas, K. D., et al. Medicinal potential of garcinia species and their compounds. Molecules. 2020 Jan; 25(19): 4513.

13. Sonia, S., Ruckmani, K., Sivakumar, M. Antimicrobial and antioxidant potentials of biosynthesized colloidal zinc oxide nanoparticles for a fortified cold cream formulation: a potent nanocosmeceutical application. Materials Science and Engineering: C. 2017 Oct 1; 79: 581-589.

14. Zare, E., Pourseyedi, S., Khatami, M., Darezereshki, E. Simple biosynthesis of zinc oxide nanoparticles using nature's source, and it's in vitro bio-activity. Journal of Molecular Structure. 2017 Oct 15; 1146: 96-103.

15. Singh, D., Rathod, V., Ninganagouda, S., Hiremath, J., Singh, A. K., Mathew, J. Optimization and characterization of silver nanoparticle by endophytic fungi Penicillium sp. isolated from Curcuma longa (turmeric) and application studies against MDR E. coli and S. aureus. Bioinorganic Chemistry and Applications. 2014 Jan 1; 2014.

16. Lokapur, V., Jayakar, V., Shantaram, M. Preliminary phytochemical screening, physicochemical analysis and invitro antioxidant activity of selected Holigarna speciesEndemic plant species of Western Ghats. Biomedicine. 2020; 40(4): 460-466.

17. Sudha, K. G., Ali, S., Karunakaran, G., Kowsalya, M., Kolesnikov, E., Rajeshkumar, M. P. Eco-friendly synthesis of $\mathrm{ZnO}$ nanorods using Cycas pschannae plant extract with excellent photocatalytic, antioxidant, and anticancer nanomedicine for lung cancer treatment. Applied Organometallic Chemistry. 2020 Apr; 34(4): e5511.

18. Rashidi, M., Seghatoleslam, A., Namavari, M., Amiri, A., Fahmidehkar, M. A., Ramezani, A., et al. Selective cytotoxicity and apoptosis-induction of Cyrtopodion scabrum extract against digestive cancer cell lines. International Journal of Cancer Management. 2017; 10(5): 7.

19. Malaikozhundan, B., Vaseeharan, B., Vijayakumar, S., Pandiselvi, K., Kalanjiam, M. A., Murugan, K., et al. Biological therapeutics of Pongamia pinnata coated zinc oxide nanoparticles against clinically important pathogenic bacteria, fungi and MCF-7 breast cancer cells. Microbial Pathogenesis. 2017 Mar 1; 104: 268-277.

20. Revathi, M., Catharin sara, S., Manonmani, R., Claudio Medoona Rigley. Fourier transform infrared spectroscopic analysis of ethanolic leaf extract of Alternanthera sessilis (L.) and Trigonella foenum-graecum (L.). Indian Journal of Applied Research. 2019; 9(2): 45-46.

21. Iqbal, M. R., Asri, I. T., Rakhmah, S., Diantoro, M. Dielectric properties of $\mathrm{TiO} 2$ nanoparticles doped flavonoid extract of Pterocarpus indicus willd (PIW) latex. InJournal of Physics: Conference Series 2018 Sep 1 (Vol. 1093, No. 1, p. 012042). IOP Publishing.

22. Hassen, H. H., Salim, E. T., Taha, J. M., Mahdi, R. O., Numan, N. H., Khalid, F. G., et al. Fourier transform infrared spectroscopy and photo luminance results for Zno NPs prepared at different preparation condition using LP-PLA technique. International Journal of Nanoelectronics and Materials. 2018; 11: 65-72.

23. Chaudhary, R. G., Sonkusare, V. N., Bhusari, G. S., Mondal, A., Shaik, D. P., Juneja, H. D. Microwave-mediated synthesis of spinel $\mathrm{CuAl} 2 \mathrm{O} 4$ nanocomposites for enhanced electrochemical and catalytic performance. Research on Chemical Intermediates. 2018 Mar; 44(3): 2039-2060.

24. Gomathi, A. C., Rajarathinam, S. X., Sadiq, A. M., Rajeshkumar, S. Anticancer activity of silver nanoparticles synthesized using aqueous fruit shell extract of Tamarindus indica on MCF-7 human breast cancer cell line. Journal of Drug Delivery Science and Technology. 2020 Feb 1; 55: 101376. 
25. Sethi, S., Joshi, A., Arora, B., Bhowmik, A., Sharma, R. R., Kumar, P. Significance of FRAP, DPPH, and CUPRAC assays for antioxidant activity determination in apple fruit extracts. European Food Research and Technology. 2020 Mar; 246(3): 591-598.

26. Prieto, P., Pineda, M., Aguilar, M. Spectrophotometric quantitation of antioxidant capacity through the formation of a phosphomolybdenum complex: specific application to the determination of vitamin E. Analytical Biochemistry. 1999 May 1; 269(2): 337-41.

27. Salari, S., Bahabadi, S. E., Samzadeh-Kermani, A., Yosefzaei, F. In-vitro evaluation of antioxidant and antibacterial potential of greensynthesized silver nanoparticles using Prosopis farcta fruit extract. Iranian Journal of Pharmaceutical Research: IJPR. 2019; 18(1): 430.

28. Izuegbuna, O., Otunola, G., Bradley, G. Chemical composition, antioxidant, anti-inflammatory, and cytotoxic activities of Opuntia stricta cladodes. Plos one. 2019 Jan 29; 14(1): e0209682. 